University of Rhode Island

DigitalCommons@URI

Open Access Dissertations

2014

\title{
MOLECULAR INTERACTION IN CARBOXYLESTERASES-BASED CATALYSIS: ONTOGENIC EXPRESSION AND INDUCTION THROUGH A NOVEL ELEMENT
}

Yi-Tzai Chen

University of Rhode Island, roy_ytchen@my.uri.edu

Follow this and additional works at: https://digitalcommons.uri.edu/oa_diss

Recommended Citation

Chen, Yi-Tzai, "MOLECULAR INTERACTION IN CARBOXYLESTERASES-BASED CATALYSIS: ONTOGENIC EXPRESSION AND INDUCTION THROUGH A NOVEL ELEMENT" (2014). Open Access Dissertations. Paper 275.

https://digitalcommons.uri.edu/oa_diss/275

This Dissertation is brought to you for free and open access by DigitalCommons@URI. It has been accepted for inclusion in Open Access Dissertations by an authorized administrator of DigitalCommons@URI. For more information, please contact digitalcommons-group@uri.edu. 
MOLECULAR INTERACTION

IN CARBOXYLESTERASES-BASED CATALYSIS:

ONTOGENIC EXPRESSION AND

INDUCTION THROUGH A NOVEL ELEMENT

BY

YI-TZAI CHEN

\begin{abstract}
A DISSERTATION SUBMITTED IN PARTIAL FULFILLMENT OF THE REQUIREMENTS FOR THE DEGREE OF DOCTOR OF PHILOSOPHY

IN
\end{abstract}

BIOMEDICAL AND PHARMACEUTICAL SCIENCES

UNIVERSITY OF RHODE ISLAND

2014 
DOCTOR OF PHILOSOPHY DISSERTATION

OF

Yi-Tzai Chen

APPROVED:

Dissertation Committee:

Major Professor: Bingfang Yan

Ruitang Deng

Joel M. Chandlee

Nasser H. Zawia

DEAN OF THE GRADUATE SCHOOL

UNIVERSITY OF RHODE ISLAND

2014 


\begin{abstract}
Carboxylesterases (CES) catalyze both hydrolytic and synthetic reactions and play important roles in drug metabolism and lipid mobilization. Many factors such as age and dietary supplements have been shown to regulate the CES expression. The expression of CES1 shows the developmental regulation and is highly induced by antioxidants. The goals of this project were to determine whether CES2, like CES1, is developmentally regulated and to investigate how antioxidants induced the expression of CES1 at the molecular level.
\end{abstract}

The ontogenic studies showed the mRNA levels of CES2 exhibited a postnatal surge (1-31 days versus 35-70 days) in both liver and duodenum. The levels of CES2 protein increased with age as well. However, individual donor multi-sampling CES2 expression studies showed the significant correlation between the duodenum and jejunum but insignificant correlation between the liver and duodenum. Moreover, the metabolic enzyme cytochrome P450 3A4 (CYP3A4) which share substrates with CES2 in many case have a comparable age related expression pattern but the mRNA level of CYP3A4 in the duodenum showed otherwise.

The mechanistic studies on CES1 induction used the dissected regulatory sequence of the CES1A1 gene to locate the element supporting the transactivation. A novel element was identified and designated as sensitizing/antioxidant response element 
(S/ARE). Comparing with the known antioxidant element ARE4, the novel element supported whereas the ARE4 element repressed the transactivation. The Electrophoretic mobility shift assay and Chromatin immunoprecipitation experiments demonstrated that the S/ARE element serves as a major site to interact with the CES1A1 gene and both elements were bound by nuclear factor-E2 related factor-2 (Nrf2).

In conclusion, CES2 and CYP3A4 are expressed under developmental regulation and whether the regulation occurs in a gene-dependent or an organ-dependent manner. Both positive and negative Nrf2 response elements exist even within the same gene. The identification of ARE4 supported Nrf2 repression, given the fact that Nrf2 is generally considered to confer transactivation activity. 


\section{ACKNOWLEDGMENTS}

I would like to acknowledge my teachers, friends and family for their selfless help, encourage and continued support for several years of work. Without these people, this dissertation would not have been finished.

Specifically, I would like to first express my sincere gratitude to my advisor Dr. Bingfang Yan for his inculcation, leadership and knowledge over the last six years. He not only thought me knowledge, but also set up example with meticulous spirit in academia. I extremely fortunate to completed projects with him.

I would also like to acknowledge my dissertation committee members, Dr. Ruitang Deng, Dr. Joel M. Chandlee, Dr. Marta Gomez-Chiarri and Dr. Wei Lu, for their time, guidance and valuable suggestions for projects and reviewed the manuscripts.

I would also thank all of the members of Dr. Yan's lab for their useful suggestions, friendship and selfless help. Special thanks to Dongfang Yang, Deshi Shi and Jian Yang for teaching me important techniques to finish my projects.

As an international student, I would to acknowledge the department of Biomedical and Pharmaceutical Sciences at the University of Rhode Island for giving me opportunity to study for my doctorate degree.

Thanks to my parents for bring me up and their encouragement in my overseas study and life even they were not with me during the whole period.

And finally, I am grateful to my wife Chien-Hua Liu, who gives me the feeling of a warm family in overseas life and supports me finish my degree. 


\section{PREFACE}

Chapter 2 has been prepared by Chen, Y. T \& Yan, B.. Manuscript format is in use.

Chapter 3 was originally published by Chen, Y. T., Shi, D., Yang, D., \& Yan, B. (2012). Antioxidant sulforaphane and sensitizer trinitrobenzene sulfonate induce carboxylesterase-1 through a novel element transactivated by nuclear factor-E2 related factor-2. Biochem Pharmacol, 84(6), 864-871. Published manuscript text, supplemental text and figures of unpublished experimentation, results, and discussion have been included. Manuscript format is in use. 


\section{TABLE OF CONTENTS}

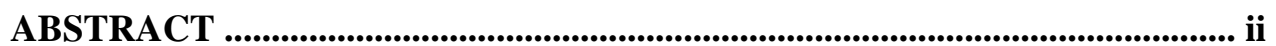

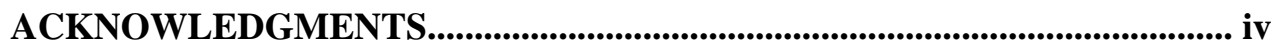

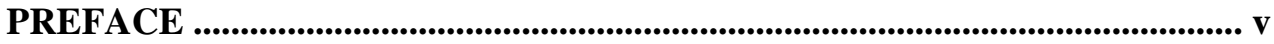

TABLE OF CONTENTS...................................................................................... vi

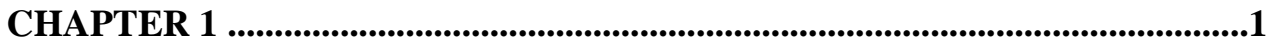

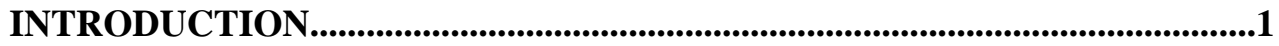

1. Overview of carboxylesterases....................................................................................... 1

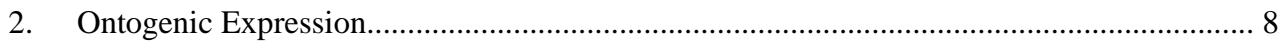

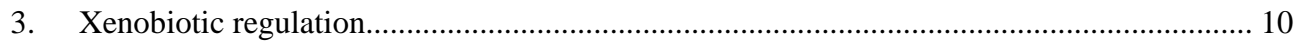

4. Functional consequence of carboxylesterase..................................................................... 14

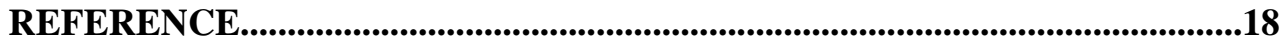

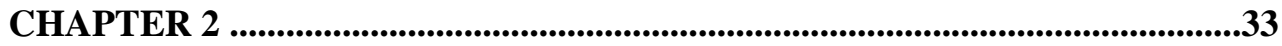

ONTOGENIC EXPRESSION OF CARBOXYLESTERASE-2 AND

CYTOCHROME P450 3A4 IN LIVER AND DUODENUM: POSTNATAL

SURGE AND ORGAN-DEPENDENT REGULATION......................................33

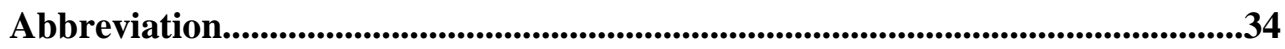

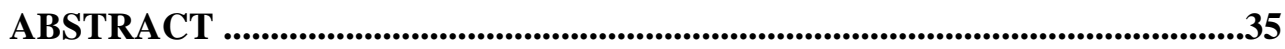

1. INTRODUCTION.....................................................................................................36

2. MATERIALS AND METHODS... .................................................................. 38

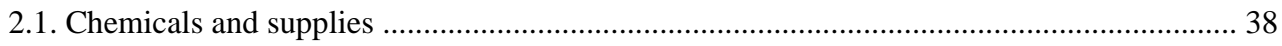

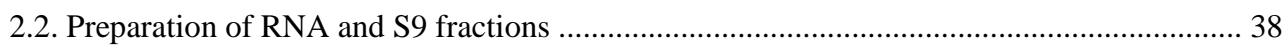


2.3. Reverse transcription-quantitative polymerase chain reaction (RT-qPCR)

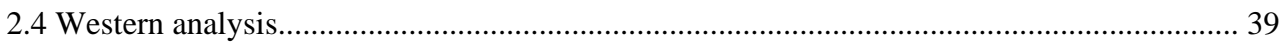

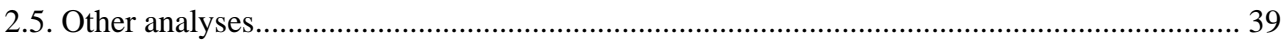

3. RESULTS............................................................................................................... 41

3.1. Expression of CES2 and CYP3A4 mRNA as a function of age ....................................... 41

3.2. Correlation of ontogenic expression between hepatic CES2 and CYP3A4 ....................... 41

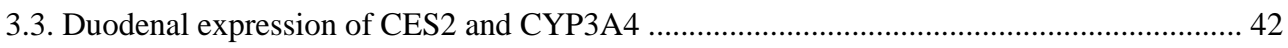

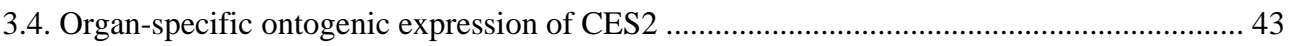

4. DISCUSSION

Footnontes.............................................................................................................. 49

REFERENCE

LEGENDS FOR FIGURES....................................................................60

CHAPTER 3 ...................................................................................................... 66

ANTIOXIDANT SULFORAPHANE AND SENSITIZER TRINITROBENZENE

SULFONATE INDUCE CARBOXYLESTERASE-1 THROUGH AN INVERSE

ELEMENT TRANSACTIVATED BY NUCLEAR FACTOR-E2 RELATED

FACTOR -2 ................................................................................... 66

1 ABSTRACT

2 INTRODUCTION .................................................................................. 68

3 RESULTS.................................................................................. 70

3.1 CES1 induction by SFN and TNBS in primary cultures and cell lines...................................

70

3.2 Stimulation of the CES1A1 promoter by SFN, TNBS and Nrf2. 70 
3.4 Activation of the S/ARE element reporter by SFN, TNBS and Nrf2 ................................. 73

3.5 Activation comparison of S/ARE element with other Nrf2 elements.................................. 73

3.6 Differential reactivity of SFN and TNBS toward Keap1 ................................................ 73

4 DISCUSSION.................................................................................................................... 75

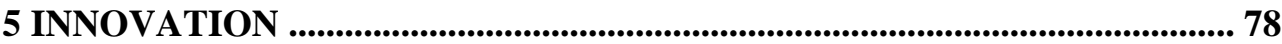

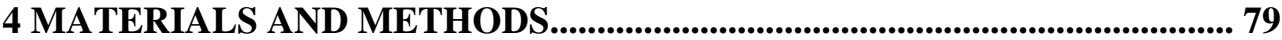

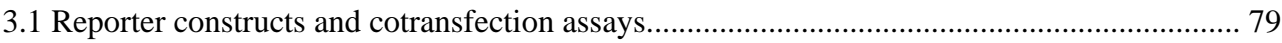

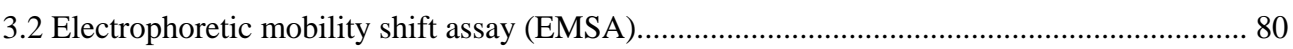

3.3 Chromatin immunoprecipitation (ChIP) ................................................................... 81

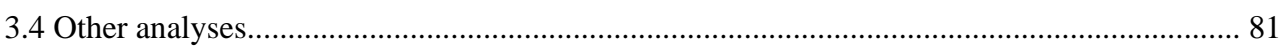

ACKNOWLEDGMENT ................................................................................ 83

STATEMENT OF CONFLICTS OF INTEREST ........................................... 83

ABBREVIATIONS......................................................................................... 83

REFERENCE................................................................................................................. 84

REFERENCE 


\section{LIST OF TABLES}

Table 1.1 Tissue distributions of CES1 and CES2 of in mammals............... 6

Table 2-1 Demographic distribution of liver donors...........................56

Table 2-2 Relative levels of liver CES2 and CYP3A4 mRNA in various age

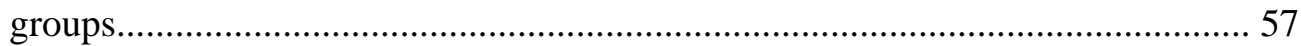

Table 2-3 Demographic distribution of duodenal donors.................................. 58

Table 2-4 Relative levels of duodenal CES2 and CYP3A4 mRNA in various age

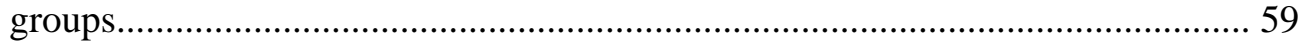

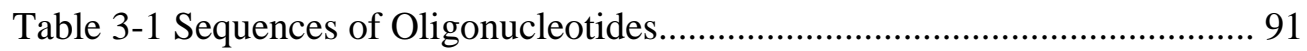




\section{LIST OF FIGURES}

Figure 1.1 Representative drugs chemical structures which are metabolized by

carboxylesterases.. 5

Figure 1.2 Example of substrate specificity of human carboxylesterases CES1 and CES2 7

Figure 1.3 Metabolic activations of irinotecan. 17

Figure 2-1 Hepatic expression of CES2 and CYP3A4 as a function of age...... 62

Figure 2-2 Correlation analyses between age and levels of CES2 or CYP3A4 mRNA. 63

Figure 2-3 Duodenal expression of CES2 and CYP3A4 as a function of age and correlation analyses. 64

Figure 2-4 Multi-sampling study on the expression of CES2 Liver, duodenal and jejunal S9 fractions.

Figure 3-1 Induction of CES1 by SFN and TNBS in human dermal fibroblast, human primary hepatocyte, and skin sarcoma line HT1080 and hepatoma line Huh7

Figure 3-2 Identification of sensitizing/antioxidant response element................ 96

Figure 3-3 Analyses of the S/ARE element by EMSA and ChIP....................... 97

Figure 3-4 Functional characterization of the S/ARE element........................... 98

Figure 3-5 Differential activation of various ARE reporters by Nrf1 and Nrf2... 99 Figure 3-6 Reactivity of mouse and human Keap1 toward sulforaphane and 


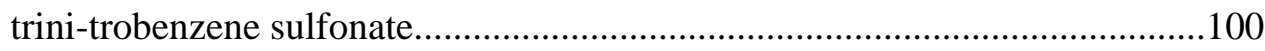

Figure 3-7 Diagrammatical presentation of regulated transcription of the CES1A1 through the S/ARE and ARE4 elements......................................................... 101 


\section{CHAPTER 1}

\section{INTRODUCTION}

\section{CARBOXYLESTERASES}

\section{Overview of carboxylesterases}

Carboxylesterases (CES, E.C.3.1.1.1) constitute a large class of enzymes that play important roles in drug metabolism and lipid mobilization [1-4]. These enzymes not only catalyze hydrolytic and synthetic reactions but also interact with other proteins. Their primary function is hydrolysis. The foreign carboxylic acid ester, amides and thioesters compounds are hydrolyzed into two components by carboxylesterases ( Figure 1.1). Hydrolysis of compounds usually causes severe changes in the electronic charge and the structure and completely affects the pharmacokinetic and pharmacodynamics characteristics of compounds [5-9]. In addition, numerous endogenous substrates such as triglycerides and cholesterol esters also are hydrolyzed by carboxylesterases [4-7] and relocate to different organelles through the re-esterification - hydrolysis cycle [10].

Multiple forms of carboxylesterases are expressed in all mammalian species. Based 
on the current approach, there are six families of all mammalian carboxylesterases, CES1, CES2, CES3, CES4, CES5, and CES6 and the members of each family share at least $60 \%$ of the sequence identity [6]. The two major families of the carboxylesterases are CES1 and CES2. The largest number of carboxylesterases belong to CES1 and eight subfamilies have been assigned [6]. The CES1 of humans, rabbits and monkeys belong to the CES1A subfamily and the CES1 of the mice, rats and hamsters are covered by CES1B. The CES1 of pigs, dogs and cats are members of CES1C [11-18]. Almost all CES1 subfamilies are expressed mainly in the liver expect CES1G $[16,19]$. In contrast, CES2 are expressed mainly in the intestines, especially in the small intestines. The CES2 family contains human (CES2A1), rat (CES2A10), mice (CES2A6) and rabbit isoenzymes (Table 1.1) [20-27].

There are seven distinct carboxylesterase genes found in the human genome, CES1A1, CES1A2, CES1A3, CES2, CES3, CES5 and CES6 respectively [5, 28, 29]. With $39-44 \%$ sequences identity $[28,29]$, the major differences between the CES1A1 and CES1A2 genes are in the promoters and leader sequence regions. Their functional mature proteins have four different amino acids in the signal peptide. The CES1A3 gene is considered a pseudo gene because of a premature stop codon. Humans can only express either CES1A2 or CES1A3. Unlike the CES1 family, there is only one 
member from each CES2, CES3, CES5 and CES6 expressed in humans [5]. The CES1 is found as a trimer or hexamer and the CES2 and CES3 exist as a monomer. The CES2 gene is expressed at different levels of mRNA and in proteins in different tissues through their transcription by three alternative promoters and two in-frame ATG's [30]. CES3 has 40\% identical sequences compared with CES1 and CES2. However, it shows very low activity with commonly used substrates [31]. CES5 and CES6 have more glycosylation sites than others CESs and both of them are the secretory protein. The activities of CES5 and CES6 remain unclear.

The human liver expresses higher level of carboxylesterases than other organs and shows the highest overall carboxylesterase activity. In the liver, larynx, esophagus and lungs, CES1 has been found. CES2 is mainly found in the gastrointestinal track, the kidney and the liver (Table 1.1). CES3 shows a low level in the trachea, intestine and placenta [32]. In contrast, the rodents contain abundant serum carboxylesterases and none of common human carboxylesterases (CES1, CES2 and CES3) have been found in normal serum [33].

The substrate specificity of carboxylesterases is considered to be ample and overlapping. The substrate specificity of two major human carboxylesterases isozymes (CES1 and CES2) have been characterized in the past decade $[3,5,6,34]$. 
The substrates of CES1 generally have a small alcohol moiety and a large acyl moiety. In contrast, substrates of CES2 have a large alcohol moiety and a small acyl moiety (Figure 1.4). For example, CES1 rather than CES2 rapidly hydrolyzes methylphenidate since the acyl moiety (methylphenidate carboxylate) is much larger than the alcohol moiety (methanol) [7]. In the antiplatelet agent, prasugrel, the acyl moiety is much smaller than the alcohol moiety, so it is mostly hydrolyzed by CES2 [35]. If the compound has more than one ester bonds, it also fit this alcohol/acid size based preference. For example, cocaine contains two ester bonds and can be hydrolyzed to ecgonine, methanol, and benzoic acid. CES1 breaks the ester bond which connects the largest acid (ecgonine) and the small alcohol (methanol) and CES2 hydrolyzes benzoate - ecgoninyl ester (Figure 1.). However, there are some exceptions to this alcohol/acid size based rule. 
<smiles>CCOC(=O)C1=C[C@@H](OC(CC)CC)[C@H](NC(C)=O)[C@H](N)C1</smiles>

Oseltamivir

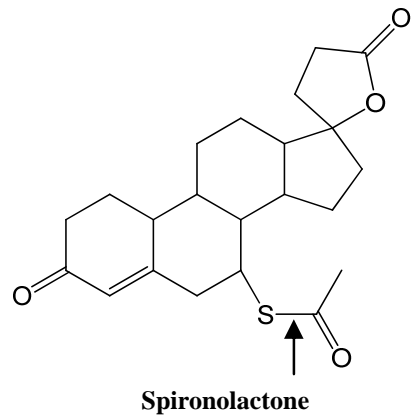

Spironolactone<smiles>CCO[PH](C)(=O)(OCC)Oc1ccc([N+](=O)[O-])cc1</smiles>

Paraoxon

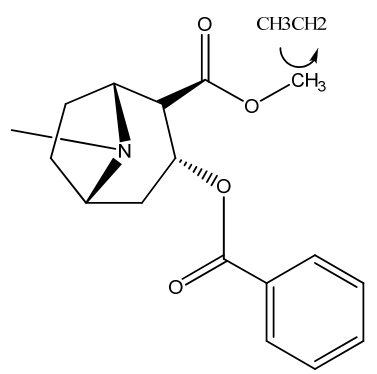

Transesterification of Cocaine

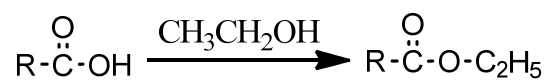

Fatty acid ethyl ester synthesis

Figure 1.1 Representative drugs chemical structures which are metabolized by carboxylesterases. The arrows show chemical bonds which are hydrolyzed by carboxylesterases. 


\begin{tabular}{|c|c|c|c|c|c|}
\hline Species & Isozyme & Liver & Small intestine & Kidney & Lung \\
\hline Mouse & CES1 & +++ & - & +++ & +++ \\
& CES2 & +++ & +++ & +++ & - \\
Rat & CES1 & +++ & - & +++ & +++ \\
& CES2 & - & +++ & - & - \\
Hamster & CES1 & +++ & - & +++ & NT \\
& CES2 & +++ & +++ & - & NT \\
Guinea Pig & CES1 & +++ & +++ & ++ & NT \\
\multirow{3}{*}{ Beagle Dog } & CES2 & - & + & - & NT \\
& CES1 & +++ & - & NT & +++ \\
Monkey & CES2 & ++ & - & - & + \\
& CES1 & +++ & ++ & + & NT \\
Human & CES2 & + & +++ & + & NT \\
& CES1 & +++ & + & +++ & ++ \\
\hline
\end{tabular}

-, undetectable, +, weakly expressed, ++, moderately expressed, +++, strongly expressed, NT, not tested

Table 1.1 Tissue distributions of CES1 and CES2 in mammals [32]. 

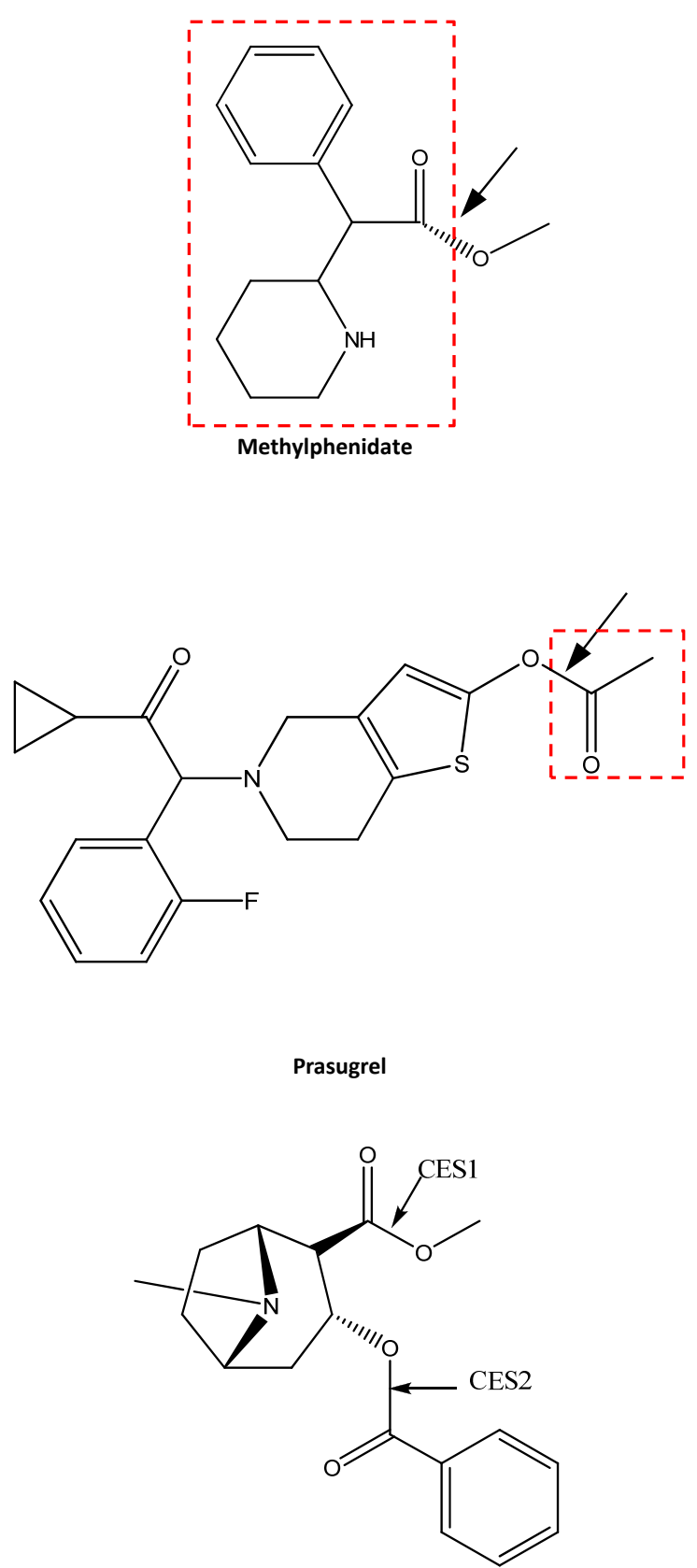

Cocaine

Figure 1.2 Examples of substrate specificity of human carboxylesterases CES1 and CES2. The arrows indicate bonds hydrolyzed by carboxylesterases and the boxes show the acid moieties of compounds. 


\section{Ontogenic Expression}

The expression of carboxylesterases shows developmental regulation in humans and rodents. During developmental stages, the human hydrolytic capacity shows an early surge in the neonatal stage and remains high through adolescence [36, 37]. CES1 mRNA has a postnatal surge in first two months [36]. In addition, adult humans express significantly higher carboxylesterase than children and children express much higher CES than fetuses. Large inter-individual variability (mRNA (430-fold), protein (100-fold) and hydrolytic activity (127-fold)) are found in the child and fetal groups but not in the adult group. That indicates the pharmacokinetics parameters of ester drugs in children may vary widely and the dosage of ester drugs needs to be carefully adjusted in children. [37]

CES1 expression shows a surge during post-neonatal stage. The mRNA and protein of the CES1 increases 4-7-fold in the hydrolysis and the expression analyses between the 1-31days and 35-70days groups. However, the other 3 pediatric groups (35-70, 89-119, 123-198) show similar levels. The 1-31d group and other 3 pediatric groups show only $10 \%$ and $50 \%$ of the expression level of adult group [37]. Based on these results, dosing regimens of ester drugs should be extra carefully monitored to prevent the possible side effects [37]. 
For the rat, there are no hydrolases A or B. Two major rat carboxylesterases are expressed in one to two weeks old rats [38]. Their intrinsic hydrolytic clearance is only $3 \%$ of adults. The clearance of four weeks old rats is less than half that of adults rats [39]. Moreover, animals are extremely sensitive to pesticides such as organophosphates and pyrethroids. Carboxylesterases detoxify them through hydrolysis or a scavenging mechanism. Interestingly, the inducibility of carboxylesterases shows an inverse relationship with age. The mRNA, protein and catalytic levels of six major carboxylesterases in neonatal mice (10 days of age) show a greater extent of induction than the adult mice after phenobarbital treatment [40]. 


\section{Xenobiotic regulation}

The catalytic activity of carboxylesterases can be manipulated by activators or inhibitors[57]. Pinacolone has been observed to increase in vitro and in vivo activities of carboxylesterases [58]. Acetone, a commonly used solvent, also shows the ability to enhance enzyme activity by increasing the accessibility of the substrate [58].

Chemicals induce or suppress the expression of carboxylesterase through different signaling pathways. There are various regulation pathways of induction which may lead to the differences. The inducers of carboxylesterases expression show differences in species in induction. Some factors which regulate the expression show the species differences and some do not. The glucocorticoid drug, dexamethasone, increases the expression of human carboxylesterases [41] but decreases the various rat carboxylesterases even as low as the nanomolar (nM) level [42]. On the other hand, phenobarbital, the most widely used anticonvulsant, induces the expression of carboxylesterases across species $[41,43]$ through the constitutive androstane receptor (CAR) and pregnane $\mathrm{X}$ receptor pathways (PXR) [44, 45]. Guggulsterone upregulates the expression of human carboxylesterases through transcription factor, nuclear factor (erythroid-derived 2)-like 2 (Nrf2) [46-48]. Moreover, 3-methylcholaanthrene is a 
ligand of the aryl hydrocarbon receptor (AhR) and only increases the enzyme in rats [49].

Compounds with similar structures, may not have the same regulatory effect. Both dexamethasone and pregnenolone $16 \alpha-$ carbonitrile (PCN) contain cyclopenta[a]phenanthrene as a basic structure. However, dexamethasone suppresses carboxylesterases expression and PCN moderately induce the expression [19, 42]. Some chemicals have similar ability to induce the cytochrome P450 (CYP) enzymes but may have the reverse effect in regulating carboxylesterases. For example, isoniazid and streptozotocin, inducers of CYP2E1, show the opposite effect of carboxylesterases. Streptozotocin is a weak inducer and isoniazid strongly suppresses the expression $[19,50] .3$ - methylcholanthrene and $\beta$ - naphthoflavone induce carboxylesterases but have the opposite effect of CYP 1A. The first compound induces the hydrolase $\mathrm{S}$ but the second one suppresses it $[19,50]$.

Antioxidants and sensitizers are two types of chemicals also show the induction of CES. The induction of this carboxylesterase by antioxidants is mediated by Nrf2 [22]. This transcription factor recognizes the antioxidant response element (ARE) and confers transactivation [23]. RNA interference against Nrf2 cancels CES1 induction by antioxidants [22]. The majority of skin sensitizers, on the other hand, are 
sulfhydryl reactive agents and have been $\mathrm{n}$ to react with Kelch-like ECH associated protein-1 (Keap1) $[18,21]$, an inhibitor of Nrf2. The Kelch-like ECH-associated protein 1 (Keap1) is a cysteine rich protein and serves as a regulator of Nrf2. Keap1 and Nrf2 play a central role in the protection of cells against antioxidants and sensitizers through inducing expression of many cytoprotective genes such as carboxylesterase1. Under uninduced conditions, $\mathrm{Nrf2}$ is ubiquitinated by the complex and rapidly degraded in proteasomes. This degradation processes regulate $\mathrm{Nrf} 2$ protein and induce stabilization of Nrf2. Upon exposure to antioxidants and sensitizers, these small molecules interact with the reactive cysteine residues of Keap1 and lead to dissociation of Nrf2 from Keap1-Nrf2 complex. Nrf2 translocates from cytoplasm to nucleus and transactivates target genes Nrf2 show transactions through binding with antioxidant response element of (ARE) in the promoter regions of upstream regulatory sequences [51-54]. Interaction with Keap1 by sensitizers leads to Nrf2 activation. Different patterns of cysteine modification of Keap1 show distinct biological outputs $[51,53]$. The magnitude of the activation was correlated with their sensitizing potency [18].

There are three different types of inhibition of activity. The first type of inhibition is competitive inhibition. That means the ester compounds metabolized by the same 
carboxylesterases and causes the hydrolysis rates to vary. The typical example is the interaction between clopidogrel and oseltamivir. Both of them are substrates of CES1, but clopidogrel has a higher hydrolysis rate than oseltamivir [34]. Based on that, oseltamivir has as low as $10 \%$ of the normal hydrolysis rate when the same concentration of clopidogrel is present. Oseltamivir is the prodrug and only the hydrolysis metabolite has a therapeutic effect with lower toxicity. When oseltamivir is administered with clopidogrel, the therapeutic outcome is decreased around $90 \%$ and the neurotoxicity is increased [55-57]. Serine enzyme inhibitors are the second type of CES inhibitors. This type of inhibitors can irreversibly bind and change the active-site serine residues. Transitional analog inhibitors are the third type of inhibition. They reversibly interact with the active-site serine residues [34, 58-62]. 
4. Functional consequence of carboxylesterase

Carboxylesterases are hydrolytic enzymes and functionally interact with other metabolic enzymes to clear xenobiotics. The pharmacogenomics of carboxylesterases is an important issue because CES leads to one of the first steps of the biotransformation pathway. The metabolites of CES associated with other enzymes and transporters form complicated networks. Therefore, the variability of CES may link to the significant clinical outcomes reported [63-67].

Many drugs are metabolized by multiple enzymes such as the carboxylesterases and cytochrome P450 (CYP) systems. The availability of a drug is usually determined by hydrolysis, because it happens faster than other reactions. The clinical effect of some ester prodrugs depends on the competition of hydrolysis by CES and oxidation by CYP. For example, clopidogrel, an antiplatelet agent, loses its pharmacological activity by hydrolysis by CES1 [3] but activates by CYP2C19, CYP3A4 and to a lesser extent, other CYP enzymes (Figure 1.) [35, 68-70]. Around 95\% of clopidogrel undergoes the hydrolysis and only $5 \%$ is oxidized to active metabolite [3]. The active metabolite interacts with the purinergic receptor P2Y, G-protein coupled, 12 (P2Y12 receptor) and partitions them out of lipid rafts [71]. On the other hand, prasugrel, another antiplatelet agent, has to be metabolized by CES2 then by multiple CYP 
enzymes and becomes finally an active compound [35, 68]. Other antiplatelet agent, acetylsalicylic acid, is also hydrolyzed by CES. After hydrolyzing it, its hydrolytic metabolite loses $90 \%$ of antiplatelet abilities. The combination of these substrates of CES enzymes may increase their antiplatelet abilities and cause unexpected clinical effects. Iirinotecan, anticancer agent, a carboxylic acid ester prodrug, is rapidly hydrolyzed by CES2 to the active metabolite SN-38 to kill cells. On the hand, Iirinotecan also undergo metabolism by CYP 3A4. More importantly, the metabolites have different functionality. Iirinotecan metabolized by CES2 represents the activation and metabolized by 3A4 represents the inactivation [72] (Figure 1.4).

Beside the pharmacological interactions, induction of CES1 may have pathophysiological significance as well. CES1 hydrolyzes many endogenous esters [2, 4, 5]. Hydrolysis of cholesterol esters increases free cholesterol and the synthesis of bile acids to eliminate excessive cholesterol [4]. On the other hand, the increasing of hydrolyzing triglycerides and cholesterol esters may increases the synthesis and secretion of very low density lipoprotein (VLDL) and low density lipoprotein (LDL). Indeed, high CES1 activity has been shown to facilitate VLDL maturation $[10,73,74]$. Transgenic expression of human CES1 in mice leads to increased secretion of apoB proteins and plasma triglycerides [10]. Elevated levels of LDL increase the risk of 
developing atherosclerosis [75]. Moreover, young patient treated with phenobarbital,

a CES1 inducer, has been observed to have higher plasma total cholesterol and low-density-lipoprotein cholesterol [76]. Therefore, excessive induction of CES1 without enhancing bile acid synthesis likely has a detrimental effect. 


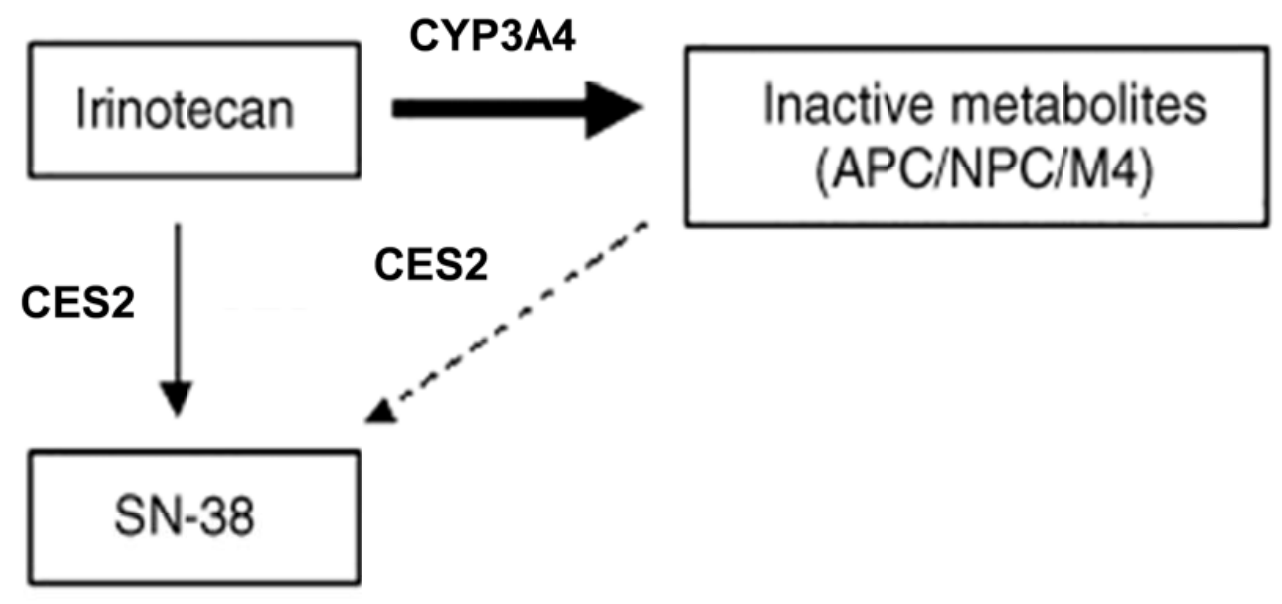

Active metabolite

Figure 1.3 Metabolic activations of irinotecan [72]. 


\section{Reference:}

[1] E. Wei, Y. Ben Ali, J. Lyon, H. Wang, R. Nelson, V.W. Dolinsky, J.R. Dyck, G. Mitchell, G.S. Korbutt, R. Lehner, Loss of TGH/Ces3 in mice decreases blood lipids, improves glucose tolerance, and increases energy expenditure, Cell metabolism, 11 (2010) 183-193.

[2] R.S. Holmes, M.W. Wright, S.J. Laulederkind, L.A. Cox, M. Hosokawa, T. Imai, S. Ishibashi, R. Lehner, M. Miyazaki, E.J. Perkins, P.M. Potter, M.R. Redinbo, J. Robert, T. Satoh, T. Yamashita, B. Yan, T. Yokoi, R. Zechner, L.J. Maltais, Recommended nomenclature for five mammalian carboxylesterase gene families: human, mouse, and rat genes and proteins, Mammalian genome : official journal of the International Mammalian Genome Society, 21 (2010) 427-441.

[3] M. Tang, M. Mukundan, J. Yang, N. Charpentier, E.L. LeCluyse, C. Black, D. Yang, D. Shi, B. Yan, Antiplatelet agents aspirin and clopidogrel are hydrolyzed by distinct carboxylesterases, and clopidogrel is transesterificated in the presence of ethyl alcohol, J Pharmacol Exp Ther, 319 (2006) 1467-1476.

[4] B. Zhao, R. Natarajan, S. Ghosh, Human liver cholesteryl ester hydrolase: cloning, molecular characterization, and role in cellular cholesterol homeostasis, Physiological genomics, 23 (2005) 304-310. 
[5] S.P. Sanghani, P.C. Sanghani, M.A. Schiel, W.F. Bosron, Human carboxylesterases: an update on CES1, CES2 and CES3, Protein Pept Lett, 16 (2009) 1207-1214.

[6] T. Satoh, M. Hosokawa, Structure, function and regulation of carboxylesterases, Chem Biol Interact, 162 (2006) 195-211.

[7] T. Imai, M. Taketani, M. Shii, M. Hosokawa, K. Chiba, Substrate specificity of carboxylesterase isozymes and their contribution to hydrolase activity in human liver and small intestine, Drug Metab Dispos, 34 (2006) 1734-1741.

[8] S.C. Laizure, V. Herring, Z. Hu, K. Witbrodt, R.B. Parker, The role of human carboxylesterases in drug metabolism: have we overlooked their importance?, Pharmacotherapy, 33 (2013) 210-222.

[9] G.M. Markey, Carboxylesterase 1 (Ces1): from monocyte marker to major player, Journal of clinical pathology, 64 (2011) 107-109.

[10] E. Wei, M. Alam, F. Sun, L.B. Agellon, D.E. Vance, R. Lehner, Apolipoprotein B and triacylglycerol secretion in human triacylglycerol hydrolase transgenic mice, $\mathrm{J}$ Lipid Res, 48 (2007) 2597-2606.

[11] T. Furihata, M. Hosokawa, N. Koyano, T. Nakamura, T. Satoh, K. Chiba, Identification of di-(2-ethylhexyl) phthalate-induced carboxylesterase 1 in C57BL/6 mouse liver microsomes: purification, cDNA cloning, and baculovirus-mediated 
expression, Drug Metab Dispos, 32 (2004) 1170-1177.

[12] M. Hosokawa, K. Suzuki, D. Takahashi, M. Mori, T. Satoh, K. Chiba, Purification, molecular cloning, and functional expression of dog liver microsomal acyl-CoA hydrolase: a member of the carboxylesterase multigene family, Arch Biochem Biophys, 389 (2001) 245-253.

[13] B. Yan, D. Yang, M. Brady, A. Parkinson, Rat testicular carboxylesterase: cloning, cellular localization, and relationship to liver hydrolase A, Arch Biochem Biophys, 316 (1995) 899-908.

[14] P.M. Potter, C.A. Pawlik, C.L. Morton, C.W. Naeve, M.K. Danks, Isolation and partial characterization of a cDNA encoding a rabbit liver carboxylesterase that activates the prodrug irinotecan (CPT-11), Cancer research, 58 (1998) 2646-2651.

[15] F. Zschunke, A. Salmassi, H. Kreipe, F. Buck, M.R. Parwaresch, H.J. Radzun, cDNA cloning and characterization of human monocyte/macrophage serine esterase-1, Blood, 78 (1991) 506-512.

[16] M. Ovnic, K. Tepperman, S. Medda, R.W. Elliott, D.A. Stephenson, S.G. Grant, R.E. Ganschow, Characterization of a murine cDNA encoding a member of the carboxylesterase multigene family, Genomics, 9 (1991) 344-354.

[17] M. Robbi, H. Beaufay, J.N. Octave, Nucleotide sequence of cDNA coding for rat 
liver pI 6.1 esterase (ES-10), a carboxylesterase located in the lumen of the endoplasmic reticulum, The Biochemical journal, 269 (1990) 451-458.

[18] M. Robbi, H. Beaufay, Biosynthesis of rat liver pI-6.1 esterase, a carboxylesterase of the cisternal space of the endoplasmic reticulum, The Biochemical journal, 248 (1987) 545-550.

[19] B. Yan, D. Yang, P. Bullock, A. Parkinson, Rat serum carboxylesterase. Cloning, expression, regulation, and evidence of secretion from liver, J Biol Chem, 270 (1995) 19128-19134.

[20] T. Imai, Y. Yoshigae, M. Hosokawa, K. Chiba, M. Otagiri, Evidence for the involvement of a pulmonary first-pass effect via carboxylesterase in the disposition of a propranolol ester derivative after intravenous administration, J Pharmacol Exp Ther, 307 (2003) 1234-1242.

[21] H. Schwer, T. Langmann, R. Daig, A. Becker, C. Aslanidis, G. Schmitz, Molecular cloning and characterization of a novel putative carboxylesterase, present in human intestine and liver, Biochem Biophys Res Commun, 233 (1997) 117-120.

[22] R. Humerickhouse, K. Lohrbach, L. Li, W.F. Bosron, M.E. Dolan, Characterization of CPT-11 hydrolysis by human liver carboxylesterase isoforms hCE-1 and hCE-2, Cancer research, 60 (2000) 1189-1192. 
[23] M. Taketani, M. Shii, K. Ohura, S. Ninomiya, T. Imai, Carboxylesterase in the liver and small intestine of experimental animals and human, Life sciences, 81 (2007) 924-932.

[24] J. Yang, D. Shi, D. Yang, X. Song, B. Yan, Interleukin-6 alters the cellular responsiveness to clopidogrel, irinotecan, and oseltamivir by suppressing the expression of carboxylesterases HCE1 and HCE2, Molecular pharmacology, 72 (2007) 686-694.

[25] T. Furihata, M. Hosokawa, A. Fujii, M. Derbel, T. Satoh, K. Chiba, Dexamethasone-induced methylprednisolone hemisuccinate hydrolase: its identification as a member of the rat carboxylesterase 2 family and its unique existence in plasma, Biochemical pharmacology, 69 (2005) 1287-1297.

[26] T. Furihata, M. Hosokawa, F. Nakata, T. Satoh, K. Chiba, Purification, molecular cloning, and functional expression of inducible liver acylcarnitine hydrolase in C57BL/6 mouse, belonging to the carboxylesterase multigene family, Arch Biochem Biophys, 416 (2003) 101-109.

[27] J. Ozols, Isolation, properties, and the complete amino acid sequence of a second form of $60-\mathrm{kDa}$ glycoprotein esterase. Orientation of the $60-\mathrm{kDa}$ proteins in the microsomal membrane, J Biol Chem, 264 (1989) 12533-12545. 
[28] R.S. Holmes, L.A. Cox, J.L. Vandeberg, A new class of mammalian carboxylesterase CES6, Comp Biochem Physiol Part D Genomics Proteomics, 4 (2009) 209-217.

[29] R.S. Holmes, L.A. Cox, J.L. Vandeberg, Mammalian carboxylesterase 5: comparative biochemistry and genomics, Comp Biochem Physiol Part D Genomics Proteomics, 3 (2008) 195-204.

[30] M.H. Wu, P. Chen, B.F. Remo, E.H. Cook, Jr., S. Das, M.E. Dolan, Characterization of multiple promoters in the human carboxylesterase 2 gene, Pharmacogenetics, 13 (2003) 425-435.

[31] S.P. Sanghani, S.K. Quinney, T.B. Fredenburg, W.I. Davis, D.J. Murry, W.F. Bosron, Hydrolysis of irinotecan and its oxidative metabolites, 7-ethyl-10-[4-N-(5-aminopentanoic acid)-1-piperidino] carbonyloxycamptothecin and 7-ethyl-10-[4-(1-piperidino)-1-amino]-carbonyloxycamptothecin, by human carboxylesterases CES1A1, CES2, and a newly expressed carboxylesterase isoenzyme, CES3, Drug Metab Dispos, 32 (2004) 505-511.

[32] M. Hosokawa, Structure and catalytic properties of carboxylesterase isozymes involved in metabolic activation of prodrugs, Molecules, 13 (2008) 412-431.

[33] E. Cecchin, G. Corona, S. Masier, P. Biason, G. Cattarossi, S. Frustaci, A. 
Buonadonna, A. Colussi, G. Toffoli, Carboxylesterase isoform 2 mRNA expression in peripheral blood mononuclear cells is a predictive marker of the irinotecan to SN38 activation step in colorectal cancer patients, Clinical cancer research : an official journal of the American Association for Cancer Research, 11 (2005) 6901-6907.

[34] D. Shi, J. Yang, D. Yang, E.L. LeCluyse, C. Black, L. You, F. Akhlaghi, B. Yan, Anti-influenza prodrug oseltamivir is activated by carboxylesterase human carboxylesterase 1 , and the activation is inhibited by antiplatelet agent clopidogrel, $\mathrm{J}$ Pharmacol Exp Ther, 319 (2006) 1477-1484.

[35] E.T. Williams, K.O. Jones, G.D. Ponsler, S.M. Lowery, E.J. Perkins, S.A. Wrighton, K.J. Ruterbories, M. Kazui, N.A. Farid, The biotransformation of prasugrel, a new thienopyridine prodrug, by the human carboxylesterases 1 and 2, Drug Metab Dispos, 36 (2008) 1227-1232.

[36] H.J. Zhu, D.I. Appel, Y. Jiang, J.S. Markowitz, Age- and sex-related expression and activity of carboxylesterase 1 and 2 in mouse and human liver, Drug Metab Dispos, 37 (2009) 1819-1825.

[37] D. Yang, R.E. Pearce, X. Wang, R. Gaedigk, Y.J. Wan, B. Yan, Human carboxylesterases HCE1 and HCE2: ontogenic expression, inter-individual variability and differential hydrolysis of oseltamivir, aspirin, deltamethrin and permethrin, 
Biochemical pharmacology, 77 (2009) 238-247.

[38] V. Zancanella, M. Giantin, R.M. Lopparelli, C. Nebbia, M. Dacasto, Constitutive expression and phenobarbital modulation of drug metabolizing enzymes and related nuclear receptors in cattle liver and extra-hepatic tissues, Xenobiotica; the fate of foreign compounds in biological systems, 42 (2012) 1096-1109.

[39] S.S. Anand, K.B. Kim, S. Padilla, S. Muralidhara, H.J. Kim, J.W. Fisher, J.V. Bruckner, Ontogeny of hepatic and plasma metabolism of deltamethrin in vitro: role in age-dependent acute neurotoxicity, Drug Metab Dispos, 34 (2006) 389-397.

[40] D. Xiao, Y.T. Chen, D. Yang, B. Yan, Age-related inducibility of carboxylesterases by the antiepileptic agent phenobarbital and implications in drug metabolism and lipid accumulation, Biochemical pharmacology, 84 (2012) 232-239.

[41] W. Zhu, L. Song, H. Zhang, L. Matoney, E. LeCluyse, B. Yan, Dexamethasone differentially regulates expression of carboxylesterase genes in humans and rats, Drug Metab Dispos, 28 (2000) 186-191.

[42] D. Shi, J. Yang, D. Yang, B. Yan, Dexamethasone suppresses the expression of multiple rat carboxylesterases through transcriptional repression: evidence for an involvement of the glucocorticoid receptor, Toxicology, 254 (2008) 97-105.

[43] E.W. Morgan, B. Yan, D. Greenway, A. Parkinson, Regulation of two rat liver 
microsomal carboxylesterase isozymes: species differences, tissue distribution, and the effects of age, sex, and xenobiotic treatment of rats, Arch Biochem Biophys, 315 (1994) 513-526.

[44] C. Xu, X. Wang, J.L. Staudinger, Regulation of tissue-specific carboxylesterase expression by pregnane $\mathrm{x}$ receptor and constitutive androstane receptor, Drug Metab Dispos, 37 (2009) 1539-1547.

[45] J. Yang, B. Yan, Photochemotherapeutic agent 8-methoxypsoralen induces cytochrome P450 3A4 and carboxylesterase HCE2: evidence on an involvement of the pregnane X receptor, Toxicol Sci, 95 (2007) 13-22.

[46] D. Yang, J. Yang, D. Shi, D. Xiao, Y.T. Chen, C. Black, R. Deng, B. Yan, Hypolipidemic agent Z-guggulsterone: metabolism interplays with induction of carboxylesterase and bile salt export pump, Journal of lipid research, 53 (2012) 529-539.

[47] Y.T. Chen, D. Shi, D. Yang, B. Yan, Antioxidant sulforaphane and sensitizer trinitrobenzene sulfonate induce carboxylesterase-1 through a novel element transactivated by nuclear factor-E2 related factor-2, Biochemical pharmacology, 84 (2012) 864-871.

[48] T. Maruichi, T. Fukami, M. Nakajima, T. Yokoi, Transcriptional regulation of 
human carboxylesterase $1 \mathrm{~A} 1$ by nuclear factor-erythroid 2 related factor 2 (Nrf2), Biochemical pharmacology, 79 (2010) 288-295.

[49] D. Yang, Y. Li, X. Yuan, L. Matoney, B. Yan, Regulation of rat carboxylesterase expression by 2,3,7,8-tetrachlorodibenzo-p-dioxin (TCDD): a dose-dependent decrease in mRNA levels but a biphasic change in protein levels and activity, Toxicological sciences : an official journal of the Society of Toxicology, 64 (2001) 20-27.

[50] B.G. Lake, A.B. Renwick, M.E. Cunninghame, R.J. Price, D. Surry, D.C. Evans, Comparison of the effects of some CYP3A and other enzyme inducers on replicative DNA synthesis and cytochrome P450 isoforms in rat liver, Toxicology, 131 (1998) $9-20$.

[51] K. Taguchi, H. Motohashi, M. Yamamoto, Molecular mechanisms of the Keap1-Nrf2 pathway in stress response and cancer evolution, Genes to cells : devoted to molecular \& cellular mechanisms, 16 (2011) 123-140.

[52] H. Kumar, I.S. Kim, S.V. More, B.W. Kim, D.K. Choi, Natural product-derived pharmacological modulators of Nrf2/ARE pathway for chronic diseases, Natural product reports, 31 (2014) 109-139.

[53] T.W. Kensler, N. Wakabayashi, S. Biswal, Cell survival responses to 
environmental stresses via the Keap1-Nrf2-ARE pathway, Annual review of pharmacology and toxicology, 47 (2007) 89-116.

[54] A. Natsch, The Nrf2-Keap1-ARE toxicity pathway as a cellular sensor for skin sensitizers--functional relevance and a hypothesis on innate reactions to skin sensitizers, Toxicol Sci, 113 (2010) 284-292.

[55] J.J. Schentag, G. Hill, T. Chu, C.R. Rayner, Similarity in pharmacokinetics of oseltamivir and oseltamivir carboxylate in Japanese and Caucasian subjects, J Clin Pharmacol, 47 (2007) 689-696.

[56] M. Abe, J. Smith, A. Urae, J. Barrett, H. Kinoshita, C.R. Rayner, Pharmacokinetics of oseltamivir in young and very elderly subjects, Ann Pharmacother, 40 (2006) 1724-1730.

[57] E.V. Pindel, N.Y. Kedishvili, T.L. Abraham, M.R. Brzezinski, J. Zhang, R.A. Dean, W.F. Bosron, Purification and cloning of a broad substrate specificity human liver carboxylesterase that catalyzes the hydrolysis of cocaine and heroin, J Biol Chem, 272 (1997) 14769-14775.

[58] L.D. Hicks, J.L. Hyatt, S. Stoddard, L. Tsurkan, C.C. Edwards, R.M. Wadkins, P.M. Potter, Improved, selective, human intestinal carboxylesterase inhibitors designed to modulate 
7-ethyl-10-[4-(1-piperidino)-1-piperidino]carbonyloxycamptothecin

(Irinotecan;

CPT-11) toxicity, J Med Chem, 52 (2009) 3742-3752.

[59] T. Harada, Y. Nakagawa, R.M. Wadkins, P.M. Potter, C.E. Wheelock, Comparison of benzil and trifluoromethyl ketone (TFK)-mediated carboxylesterase inhibition using classical and 3D-quantitative structure-activity relationship analysis,

Bioorg Med Chem, 17 (2009) 149-164.

[60] C.E. Wheelock, K. Nishi, A. Ying, P.D. Jones, M.E. Colvin, M.M. Olmstead, B.D. Hammock, Influence of sulfur oxidation state and steric bulk upon trifluoromethyl ketone (TFK) binding kinetics to carboxylesterases and fatty acid amide hydrolase (FAAH), Bioorg Med Chem, 16 (2008) 2114-2130.

[61] R.M. Wadkins, J.L. Hyatt, C.C. Edwards, L. Tsurkan, M.R. Redinbo, C.E. Wheelock, P.D. Jones, B.D. Hammock, P.M. Potter, Analysis of mammalian carboxylesterase inhibition by trifluoromethylketone-containing compounds, Molecular pharmacology, 71 (2007) 713-723.

[62] W.E. Luttrell, M.C. Castle, Enhancement of hepatic microsomal esterase activity following soman pretreatment in guinea pigs, Biochemical pharmacology, 46 (1993) 2083-2092.

[63] Z. Nemoda, N. Angyal, Z. Tarnok, J. Gadoros, M. Sasvari-Szekely, 
Carboxylesterase 1 gene polymorphism and methylphenidate response in ADHD, Neuropharmacology, 57 (2009) 731-733.

[64] N. Ribelles, J. Lopez-Siles, A. Sanchez, E. Gonzalez, M.J. Sanchez, F. Carabantes, P. Sanchez-Rovira, A. Marquez, R. Duenas, I. Sevilla, E. Alba, A carboxylesterase 2 gene polymorphism as predictor of capecitabine on response and time to progression, Curr Drug Metab, 9 (2008) 336-343.

[65] R. Bellott, V. Le Morvan, V. Charasson, A. Laurand, M. Colotte, U.M. Zanger, K. Klein, D. Smith, J. Bonnet, J. Robert, Functional study of the $830 \mathrm{C}>\mathrm{G}$ polymorphism of the human carboxylesterase 2 gene, Cancer Chemother Pharmacol, 61 (2008) 481-488.

[66] S.R. Kim, K. Sai, T. Tanaka-Kagawa, H. Jinno, S. Ozawa, N. Kaniwa, Y. Saito, A. Akasawa, K. Matsumoto, H. Saito, N. Kamatani, K. Shirao, N. Yamamoto, T. Yoshida, H. Minami, A. Ohtsu, N. Saijo, J. Sawada, Haplotypes and a novel defective allele of CES2 found in a Japanese population, Drug Metab Dispos, 35 (2007) 1865-1872.

[67] E. Geshi, T. Kimura, M. Yoshimura, H. Suzuki, S. Koba, T. Sakai, T. Saito, A. Koga, M. Muramatsu, T. Katagiri, A single nucleotide polymorphism in the carboxylesterase gene is associated with the responsiveness to imidapril medication and the promoter activity, Hypertens Res, 28 (2005) 719-725. 
[68] N.A. Farid, C.D. Payne, D.S. Small, K.J. Winters, C.S. Ernest, 2nd, J.T. Brandt, C. Darstein, J.A. Jakubowski, D.E. Salazar, Cytochrome P450 3A inhibition by ketoconazole affects prasugrel and clopidogrel pharmacokinetics and pharmacodynamics differently, Clinical pharmacology and therapeutics, 81 (2007) 735-741.

[69] T.A. Clarke, L.A. Waskell, The metabolism of clopidogrel is catalyzed by human cytochrome P450 3A and is inhibited by atorvastatin, Drug Metab Dispos, 31 (2003) 53-59.

[70] W.C. Lau, P.A. Gurbel, P.B. Watkins, C.J. Neer, A.S. Hopp, D.G. Carville, K.E. Guyer, A.R. Tait, E.R. Bates, Contribution of hepatic cytochrome P450 3A4 metabolic activity to the phenomenon of clopidogrel resistance, Circulation, 109 (2004) 166-171.

[71] P. Savi, J.L. Zachayus, N. Delesque-Touchard, C. Labouret, C. Herve, M.F. Uzabiaga, J.M. Pereillo, J.M. Culouscou, F. Bono, P. Ferrara, J.M. Herbert, The active metabolite of Clopidogrel disrupts $\mathrm{P} 2 \mathrm{Y} 12$ receptor oligomers and partitions them out of lipid rafts, Proceedings of the National Academy of Sciences of the United States of America, 103 (2006) 11069-11074.

[72] F.A. de Jong, J.M. van der Bol, R.H. Mathijssen, T. van Gelder, E.A. Wiemer, A. 
Sparreboom, J. Verweij, Renal function as a predictor of irinotecan-induced neutropenia, Clinical pharmacology and therapeutics, 84 (2008) 254-262.

[73] D.R. Blais, R.K. Lyn, M.A. Joyce, Y. Rouleau, R. Steenbergen, N. Barsby, L.F. Zhu, A.F. Pegoraro, A. Stolow, D.L. Tyrrell, J.P. Pezacki, Activity-based protein profiling identifies a host enzyme, carboxylesterase 1, which is differentially active during hepatitis C virus replication, The Journal of biological chemistry, 285 (2010) $25602-25612$.

[74] H. Wang, E. Wei, A.D. Quiroga, X. Sun, N. Touret, R. Lehner, Altered lipid droplet dynamics in hepatocytes lacking triacylglycerol hydrolase expression, Molecular biology of the cell, 21 (2010) 1991-2000.

[75] P.W. Siri-Tarino, Q. Sun, F.B. Hu, R.M. Krauss, Saturated fat, carbohydrate, and cardiovascular disease, The American journal of clinical nutrition, 91 (2010) 502-509.

[76] T. Jakubus, M. Michalska-Jakubus, K. Lukawski, A. Janowska, S.J. Czuczwar, Atherosclerotic risk among children taking antiepileptic drugs, Pharmacological reports : PR, 61 (2009) 411-423. 


\title{
ONTOGENIC EXPRESSION OF CARBOXYLESTERASE-2 AND CYTOCHROME P450 3A4 IN LIVER AND DUODENUM: POSTNATAL SURGE AND ORGAN-DEPENDENT REGULATION ${ }^{1}$
}

\author{
Yi-Tzai Chen, Deshi Shi, Dongfang Yang, Yuanjun Shen and Bingfang Yan \\ Department of Biomedical Sciences \\ University of Rhode Island Kingston, \\ RI 02881
}

Affiliation: Department of Biomedical and Pharmaceutical Sciences, Center for Pharmacogenomics and Molecular Therapy, University of Rhode Island Kingston, RI 02881 
Running Title:

Address Correspondence to:

Number of Text Pages

Number of Tables

Number of Figures

Number of References

Words of Abstract

Words of Introduction

Words of Discussion
Ontogeny of carboxylesterase-2 and cytochrome P450 3A4

\author{
Dr. Bingfang Yan \\ Department of Biomedical and Pharmaceutical Sciences \\ University of Rhode Island \\ Kingston, RI 02881
}

Phone: (401) 874-5032

Fax: (401) 874-5048

E-mail: byan@uri.edu

Abbreviation: CES2, carboxylesterase-2; CYP3A4, cytochrome P450 3A4; GAPDH, glyceradehyde-3phosphate dehydrogenase; GI, gastrointestinal; PBS, phosphate buffered saline; PPAR $\alpha$, peroxisome proliferator-activated receptor- $\alpha$; RT-qPCR, reverse transcription-quantitative polymerase chain reaction. 


\begin{abstract}
Carboxylesterase-2 (CES2) and cytochrome P450 3A4 (CYP3A4) are two major drug metabolizing enzymes that play critical roles in hydrolytic and oxidative biotransformation, respectively. In many cases, CES2 and CYP3A4 share substrates such as the anticancer prodrug irinotecan and present opposite outcomes in terms of therapeutic activity. CES2 and CYP3A4 are both expressed in the liver and the gastrointestinal (GI) tract. The present study was conducted to determine whether CES2 and CYP3A4 are expressed under developmental regulation and whether the regulation occurs in an organ-dependent manner. Liver and duodenal tissues were collected from various ages. The liver tissues were divided into 5 age groups: I (1-31 days), II (35-70 days), III (89-119 days), IV (123-198) and IV ( $\geq 18$ years of age). The duodenal tissues were divided into 4 groups: D1 (1-70 days), D2 (76-141 days), D3 (163-332 days) and D4 ( $\geq 18$ years). In addition, multi-sampling (liver, duodenum and jejunum) was performed in some donors. The expression was determined at mRNA and protein levels. In the liver, the levels of CES2 and CYP3A4 mRNA exhibited a postnatal surge (group I versus II) by 2.7 and 29 fold, respectively. CYP3A4 but not CES2 mRNA in certain pediatric groups reached or even exceeded the adult level. The duodenal samples, on the other hand, showed a gene-specific expression pattern at mRNA level. The level of CES2 mRNA increased with age but the opposite was true with CYP3A4 mRNA. The levels of CES2 and CYP3A4 protein, on the other hand, increased with age in both liver and duodenum. The multi-sampling study demonstrated significant correlation of CES2 expression between the duodenum and jejunum. However, neither duodenal nor jejunal expression correlated with hepatic expression of CES2. These findings establish that developmental regulation occurs in a gene and organ-dependent manner.
\end{abstract}




\section{INTRODUCTION}

Personalized medicine is an ultimate goal of health professionals and inter-individual variability presents the major challenge to achieve this goal [1-4]. While many factors are contributing to inter-individual variability, biotransformation is recognized as one of the major contributing factors $[3,4]$. There are three types of biotransformation, commonly referred to as phase I [5], phase II [6] and phase III reactions [7]. Phase I and II reactions are accomplished by drug-metabolizing enzymes. Phase III reactions, without chemical modifications, are accomplished by drug transporters. The human genome contains $\sim 150$ biotransformation genes with known pharmacological and toxicological significance [3-7]. Many biotransformation genes are expressed in a wide range of organs and tissues. However, the highest expression of many biotransformation genes occurs in the liver and the gastrointestinal (GI) tract $[8,9]$. The expression of these genes, on the other hand, exhibits large inter-individual variability, up to 100-fold in some cases [10]. Genetic and environmental factors as well as disease status are known to regulate the expression of these genes [11-13].

We and investigators have shown that the expression of biotransformation genes is developmentally regulated in rodents and humans [14-18]. Based on immunoblotting analysis [16], one to two week old rats express no hydrolase A or B, two major rat carboxylesterases. Consistent with little expression of carboxylesterases, the intrinsic hydrolytic clearance of the pyrethroid deltamethrin in 10-day old rats is only $\sim 3 \%$ of adult rats [19]. Even in 4-week old rats, the intrinsic clearance is less than half of that of adults [19]. In addition, young animals are generally much more sensitive to pesticides such as organophosphates and pyrethroids [20,21]. Carboxylesterases are known to protect against these chemicals by hydrolysis in the case of pyrethroids or scavenging mechanism in the case of organophosphates. Human carboxylesterase-1 (CES-1) and 2 (CES2) in the liver are developmentally regulated $[15,22,23]$. 
We recently showed that the developmental regulation of CES1 in the liver consists of a postnatal surge followed by an incremental increase throughout the entire adolescence [15, 22]. Based on the level of CES1 mRNA, the postnatal surge of CES1 is completed two months after birth [22]. The present study was undertaken to determine whether the ontogenic expression pattern of CES1 represents a common phenomenon among biotransformation genes. This study focused on CES2 and cytochrome P450 3A4 (CYP3A4). CES2 and CES1 together represent as much as 90\% of hydrolytic capacity toward drugs and other xenobiotics $[24,25]$. CYP3A4 is a member of the cytochrome P450 mixed-function oxidase system [26]. This oxidase is involved in the metabolism of more than $50 \%$ drugs and other xenobiotics. CES2 and CYP3A4 are functionally linked in terms of tissue distribution and coupled metabolism. For example, both CES2 and CYP3A4 are abundantly expressed in the liver and the GI tract $[8,27,28]$. Importantly, some drugs are metabolized by both CES2 and CYP3A4. Their relative activity has profound therapeutic consequences [29]. The anticancer drug irinotecan, for example, is hydrolyzed to produce SN-38, a metabolite with potent anticancer activity. In contrast, irinotecan undergoes oxidation by CYP3A4 to produce two major oxidative metabolites: NPC (7-ethyl-10-(4-amino-1-piperidino) carbonyloxycamptothecin and APC (7-ethyl-10-[4-N-(5-aminopentanoic acid)-1-piperidino] carbonyloxycamptothecin. Both NPC and APC are less active than the parent compounds [29].

This study tested a large number of human liver and duodenal samples for the expression of CES2 and CYP3A4 by Western blotting and reverse transcription-quantitative polymerase chain reaction (RTqPCR). In the liver, the levels of CES2 and CYP3A4 mRNA exhibited a postnatal surge (group I versus II) by 2.7 and 29 fold, respectively. The duodenal samples, on the other hand, showed a gene-specific expression pattern at mRNA level. CES2 mRNA increased with age but the opposite was true with CYP3A4 mRNA. Nevertheless, CES2 and CYP3A4 protein increased with age in both liver and duodenum. The multi-sampling study demonstrated significant correlation of CES2 expression between the duodenum and jejunum. However, neither duodenal nor jejunal expression correlated with hepatic expression of CES2. 


\section{MATERIALS AND METHODS}

\subsection{Chemicals and supplies}

Ponceau S was purchased from Sigma (St. Louis, MO). TaqMan probes were from Life Technologies Corporation (Grand Island, NY). The TaqMan assay identification numbers were: CES2, Hs00187279_m1 (NM_198061); CYP3A4, Hs00604506_ml (NM_017460.3); and polymerase (RNA) II, Hs01108291_m1 (NM_000937). Random primers and M-MLV reverse transcriptase were purchased from Promega Corporation (Madison, WI). The RNAzol B reagent was from Tel-Test Inc (Friendswood, TX). Antibody against glyceradehyde-3-phosphate dehydrogenase (GAPDH) was from Abcam (Cambridge, MA). Unless otherwise specified, all other reagents were purchased from Fisher Scientific (Pittsburgh, PA).

\subsection{Preparation of RNA and S9 fractions}

A total of 102 tissue samples were used in this study including 59 liver, 33 duodenal and 10 jejunal samples. Multi-sampling was performed in 10 donors, thus, there was a total of 92 donors. Among them, 69 were pediatric (1-332 days of age) and 23 adult donors. Majority of the donors (54\%) were Caucasian-American. The tissues were acquired primarily from the University of Maryland Brain and Tissue Bank for Developmental Disorders (Baltimore, MD). Total RNA was isolated with RNAzol B and the integrity was verified by agarose gel electrophoresis described previously [30]. S9 fractions were prepared by differential centrifugation as described previously [30]. The use of the human samples was approved by the Institutional Review Board.

\subsection{Reverse transcription-quantitative polymerase chain reaction (RT-qPCR)}

Total RNA $(0.1 \mu \mathrm{g})$ was subjected to the synthesis of the first strand cDNA in a total volume of $25 \mu \mathrm{L}$

with random primers and M-MLV reverse transcriptase [15]. The reactions were conducted at $25^{\circ} \mathrm{C}$ for $10 \mathrm{~min}, 42^{\circ} \mathrm{C}$ for $50 \mathrm{~min}$ and $70^{\circ} \mathrm{C}$ for $10 \mathrm{~min}$. The cDNAs were then diluted 6 fold and qPCR was 
performed with TaqMan Gene Expression Assay as described previously [15, 23]. The PCR amplification was conducted in a total volume of $20 \mu$ l containing universal PCR master mixture $(10 \mu \mathrm{l})$, genespecific TaqMan assay mixture $(1 \mu \mathrm{l})$, and cDNA template $(3 \mu 1)$. The cycling profile was $50^{\circ} \mathrm{C}$ for 2 $\min , 95^{\circ} \mathrm{C}$ for $10 \mathrm{~min}$, followed by 40 cycles of $15 \mathrm{~s}$ at $95^{\circ} \mathrm{C}$ and $1 \mathrm{~min}$ at $60^{\circ} \mathrm{C}$, as recommended by the manufacturer. Amplification and quantification were done with the Applied Biosystems 7900HT RealTime PCR System. All samples were analyzed in triplicate and the signals were normalized to polymerase (RNA) II and then expressed as relative levels of mRNA....

\subsection{Western analysis}

S9 fractions $(8-20 \mu \mathrm{g})$ were resolved by $7.5 \%$ SDS-PAGE in a mini-gel apparatus and transferred electrophoretically to nitrocellulose membranes. In some cases, membranes were rinsed once in TBST buffer (20 mM Tris- $\mathrm{HCl}, 150 \mathrm{mM} \mathrm{NaCl}$ and $0.05 \%$ Tween 20$)$ and then blocked in $5 \%$ non-fat milk as described previously $[24,31]$. In other cases, membranes were washed once in $0.1 \%$ acetic acid solution and stained in $0.1 \%$ Ponceau $\mathrm{S}$ solution for $5 \mathrm{~min}$. The membranes were then washed twice in $5 \%$ acetic acid solution and then blocked in $5 \%$ non-fat milk. The blots were incubated with an antibody against CES2, CYP3A4 and GAPDH, respectively. The preparation of the antibodies against CES2 and CYP3A4 was described elsewhere [32]. In both cases, the antigens were peptides conjugated with keyhole limpet hemocyanin. The sequence of CES2 peptide was $\mathrm{H}_{2} \mathrm{~N}$-CQELEEPEERHTEL-COOH, and of CYP3A4 was $\mathrm{H}_{2} \mathrm{~N}-\mathrm{CVKRMKESRLEDTQKHRVDFLQ-COOH}$. The primary antibodies were subsequently localized with goat anti-rabbit IgG conjugated with horseradish peroxidase, and horseradish peroxidase activity was detected with a chemiluminescent kit (SuperSignal West Pico). The chemiluminescent signals signal was captured by Carestream 2200 PRO imager.

\subsection{Other analyses}

Protein concentrations were determined with BCA assay (Pierce) based on bovine serum albumin standard. Data are presented as mean $\pm \mathrm{SD}$. All enzymatic assays were repeated three times with the 
same microsomal preparation. Statistical analyses were performed with SPSS-PASW Statistics 20. Significant differences were tested according to Spearman for correlation or One-way ANOVA followed by a DUNCAN's test for comparison of means. In all cases, significant differences were made when $p$ values were less than 0.05 . 


\section{RESULTS}

\subsection{Expression of CES2 and CYP3A4 mRNA as a function of age}

We have shown that the expression of CES1 exhibits a two-phase developmental regulation: a fast surge in the early period after birth followed by an incremental phase toward the end of adolescence [15, 23]. This study was undertaken to determine whether the two-phase developmental regulation represents a common phenomenon among drug-metabolizing enzymes. This study focused on CES2 and CYP3A4, two major drug-metabolizing enzymes [24-26]. CES2 and CYP3A4 share many substrates with different clinical consequences [29]. We initially tested a large number of individual liver tissues collected at birth to 198 days of age. Samples were divided into several groups: I (1-31 days), II (35-70 days), III (89-119 days) and IV (123-198 days). As a control, adult livers (i.e., group V) were included. Each group had 1014 individual samples. Among them, 33 were male and 26 female donors (Table I).

The expression of CES2 and CYP3A4 was determined by RT-qPCR with a Taqman probe and Western blotting. As shown in Fig. 1 and Table II, the relative level of CES2 mRNA in group I-V was 26, 70, 88, 80 and $100 \%$, respectively. The level of CYP3A4 mRNA in these groups was 2, 65, 110, 98 and 100\%, respectively. Clearly, both genes exhibited a postnatal surge (group I versus II) with a magnitude of 2.7 and 29 fold, respectively. For CES2 mRNA, none of the postnatal groups reached the adult level. In contrast, the level of CYP3A4 mRNA in groups III and IV reached or even exceeded the adult level (Fig.

1, Table II). The levels of the corresponding proteins, on the other hand, showed a better age-dependent increase for both enzymes (Fig. 1). The expression of mRNA for both genes exhibited large interindividual variations with CYP3A4 mRNA being much greater (Fig. 1, Table I).

\subsection{Correlation of ontogenic expression between hepatic CES2 and CYP3A4}

Both CES2 and CYP3A4 mRNA exhibited a postnatal surge, however, the magnitude differed markedly

(Fig. I and Table II). In addition, the level of CYP3A4 but not CES2 mRNA in certain pediatric groups reached or even exceeded the adult level. These observations pointed to potential differences in the 
molecular mechanisms supporting the ontogenic regulation of these two genes. To shed light on this possibility, correlation studies were performed on age as well as on each other. As shown in Fig. 2A, the level of CES2 mRNA was significantly correlated with age and the correlation was slightly better during the period of 1-70 days of age $(r=0.359)$ than that of $0-198$ days $(r=0.478)$. Similar trend of correlation was detected on the level of CYP3A4 mRNA over age $(r=0.350$ versus $r=0.539)$. Importantly, the levels of CES2 and CYP3A4 mRNA were correlated well. The correlation coefficient for the period of 0198 days was 0.318 and the correlation was much improved for the period of $1-70$ days $(r=0.859)$, suggesting that the same or similar mechanism support the ontogenic expression of CES2 and CYP3A4, particularly during the first two months after birth.

\subsection{Duodenal expression of CES2 and CYP3A4}

In addition to the liver, the GI track expresses high levels of drug metabolizing enzymes [24-26]. We next tested whether the duodenum shares with the liver in the ontogenic expression of CES2 and CYP3A4. A total of 43 duodenal samples were collected and divided into I (1-70 days), II (76-141 days), III (163-332 days) and IV ( $\geq 18$ years) (Table III) with each group having 9-13 individual samples. E As shown in Fig. 3A (Left), the levels of CES2 mRNA and protein exhibited age-related increases in groups I, II and III (Fig. 3, Table III), although the increase in CES2 mRNA between group III and IV was minimal (Table III). The adult group, nevertheless, exhibited much greater individual variation in CES2 mRNA (Left of Fig. 3A). Ponceau S staining was used for the normalization of loading and transfer as

the levels of several commonly used house-keeping proteins (e.g., GAPDH) showed large group-group variations. The correlation of CES2 mRNA with age among the duodenal samples (0-332 days) was statistically significant $(p<0.017)$ and the correlation coefficient was 0.412 (Fig. 3A). Interestingly, the correlation among the $0-96$ day samples had a smaller coefficient $(r=0.283)$ and did not reach statistical significance. Overall, the correlation study demonstrated that CES2 mRNA exhibited a similar pattern of ontogenic expression in the liver and duodenum. 
In contrast to the liver, CYP3A4 mRNA in the duodenum exhibited a major difference in the age-related expression. The level of CYP3A4 mRNA in the liver was correlated positively with age (Fig. 1, Table II). However, the level of CYP3A4 mRNA decreased with age (Left of Fig. 3B, Table IV). In the duodenal samples, a 25\% decrease of CYP3A4 mRNA was detected from group I (1-70 days) to groups II (76-141 days) or III (163- 332 days). Overall, the level of CYP3A4 mRNA in the duodenal samples among pediatric donors was inversely correlated with age, although the inversed correlation did not reach the level of statistical significance $(r=-0.145, p=0.421)$. Interestingly, during the first three months after birth (1-96 days), the level of CYP3A4 mRNA showed a trend of positive correlation with age ( $\mathrm{r}=$ 0.184, $p=0.546$ ) (Fig. 3B). Nevertheless, none of the correlation coefficients reached statistical significance. Among all duodenal samples, large individual variations were detected with coefficients of variance ranging from 1.78 to 2.46 (Table IV). The adult duodenal samples, compared with group I sample, showed a $67 \%$ decrease in CYP3A4 mRNA (Left of Fig. 3B). Interestingly, the level of CYP3A4 protein in this group was much higher than that of all other duodenal groups (pediatric donors).

\subsection{Organ-specific ontogenic expression of CES2}

The studies with groups-based samples demonstrated large individual variations, although the variations tended to be smaller with the liver samples (Figs. 1 and 3). To minimize potential individual variations, we next determined the expression of CES2 in the liver and intestinal samples from the same donors. This was of significance as this study would specify whether individuals expressing relatively high levels of CES2 in the liver also express high levels of this enzyme in his/her GI track. We collected liver, duodenum and jejunum from 10 individuals. With an exception of a single adult donor, all donors were pediatric from 1 to 196 days of age. Once again, both RT-qPCR and Western blotting were used for the expression determination. CES2 mRNA but not for CES2 protein was detected in all samples. While there were exceptions, the relative abundance of CES2 protein occurred in an order of the liver, the duodenum and the jejunum (Fig. 3A). Donor 10, on the other hand, expressed the highest level of CES2 protein in the duodenum. Donor 3 expressed comparable levels of CES2 protein among all three organs 
and donor 4 did not express detectable CES2 protein in either organ. Based on the level of CES2 rnRNA, duodenal and jejunal exp白 ssion was significantly correlated with a coefficient of 0.359 (p 0.023) However neither duodenal nor jejunal exp 白 ssion was correlated liver expression (Fig. 4B) 


\section{DISCUSSION}

Individualized medicine is an ultimate goal of health professionals and inter-individual variability presents the major challenge for individualized medicine [1-4]. Biotransformation is the major contributor to individual variability $[3,4]$. In adults, the expression of drug-metabolizing enzymes is regulated largely by environmental factors, whereas in children, environmental and developmental factors are both involved in the regulatory process $[15,23]$. We have recently made a concerted effort and laid groundwork on the ontogenic expression of biotransformation genes. In this study, we tested a large number of liver and small intestinal samples from pediatric donors for the expression of CES2 and CYP3A4, two major drug-metabolizing enzymes $[24,26]$. While both genes were developmentally regulated, the overall outcomes varied depending on a gene and an organ. In the case of CES2, agedependent increases were detected in the liver and the GI tract at both mRNA and protein levels (Figs. 1 and 2). However, the age-related increases in CYP3A4 were detected at protein in both organs but not mRNA (Figs. 1 and 2).

The results described in this study, nevertheless, point to an important conclusion about ontogenic expression in human liver. Namely, the postnatal surge, although exceptions may exist, is a general phenomenon among biotransformation genes. The magnitude of the surge, on the other hand, varied depending on a gene. Based on RT-qPCR analysis, the level of CYP3A4 mRNA showed a surge by 29fold, but the level of CES2 mRNA by 2.7 fold only (Fig. 1). We previously reported a 7.1-fold postnatal surge of CES1 mRNA. The surge of CES2 and CYP3A4 mRNA represented 65-70\% of the level in adult liver, whereas in the case of CES1, it represented 50\% only [23]. Following the surge was gradual increases in mRNA expression during the 6 months after birth. However, such increases varied markedly from a gene to another. In the case of CES2, 10-20\% increases were detected from 70 to 198 days of age, but the level of CES1 mRNA was increased by only 5\% during this period. The level of CYP3A4 mRNA, on the other hand, was increased by as much as $45 \%$. As a matter of fact, the level of CYP3A4 mRNA in groups III (89-119 days) and IV (123-198 days) reached or even exceeded the adult level (Fig. 
1). In contrast, the surge of CES2 mRNA was followed by an incremental increase toward adulthood, which was similar to that of CES1 mRNA. However, the incremental phase of CES2 mRNA represented less percentage than that of CES1 (20 vs. 50\%) (23, Fig. 1).

The level of CYP3A4 but not CES2 mRNA displayed organ-specific ontogenic expression patterns. The hepatic expression of CYP3A4 mRNA, like CES2 mRNA, was correlated significantly during the first six months of life $(\mathrm{r}=0.350, p=0.027)$ (Left of Fig. 2B). Similarly to CES2 mRNA, CYP3A4 mRNA was correlated much better with age $(r=0.539, \mathrm{p}<0.014)$ when the period of the first 70 days was considered (Right of Figs. 2A and B). Importantly, levels of CES2 and CYP3A4 mRNA were correlated significantly with each other (Fig. 2C). These findings suggested that CES2 and CYP3A4 share mechanisms in ontogenic expression, at least in light of hepatic mRNA expression. In contrast, the duodenum exhibited different expression patterns between CES2 and CYP3A4 mRNA. A positive correlation during the first 70 days was detected for both genes (Right of Fig. 3). However, the overall correlation during the first 198 days was opposite. The abundance of CYP3A4 mRNA was negatively correlated with age, while the level of CES2 mRNA positively with age in the duodenum (Fig. 3).

The multi-organ sampling study provided important information on inter-organ differences in terms of gene expression. While the level of CES2 mRNA increased with age in both liver and duodenum, hepatic and duodenal levels from the same donors showed insignificant correlation (Fig. 4B). On the other hand, duodenal and jejunal levels of CES2 mRNA were significantly correlated (Fig. 4B). The insignificant correlation between the liver and small intestine suggests that the developmental regulation is mediated by different triggers in these two organs. The precise mechanisms remain to be determined, and many changes take place immediately after birth and in the early days/weeks of life, notably on hormones and food intake. On the other hand, many biotransformation genes are expressed in a rapid increasing manner such as CYP3A4 and CES1. For example, fibroblast growth factor-21 (FGF-21) is induced rapidly [33], 
and importantly the induction of FGF-21 was diminished in mice lacking functional peroxisome proliferator-activated receptor- $\alpha(\operatorname{PPAR} \alpha)[33]$.

It happens that this receptor has been implicated in the regulation of the expression of carboxylesterases in rodents $[16,34,35]$, although its involvement in the regulated expression of human carboxylesterases remains to be established. On the other hand, the CES2 promoter region contains two PPAR $\alpha$ putative elements located -907 and -256 , respectively [36]. It has been reported that the CES2 gene has three promoters, designated promoter-1, promoter-2 and promoter-3, respectively. These promoters use different transcription start sites, thus producing distinct transcripts. It appears that promoter-3 has a broad tissue activity and supports constitutive but low level of expression. In contrast, promoter 1 and promoter 2 show tissue-dependent activity. For example, promoter 1 is more active in the liver than promoter 2, and the opposite is true in the small intestine [36]. Interestingly, one of the PPAR $\alpha$ putative elements is present in promoter 1 and the other in promoter 2. Given the observation that the liver but not small intestine expresses high levels of PPAR $\alpha$ [37, 38], the element in promoter 1 is likely involved in the developmental regulation of CES2 in the liver. On the other hand, PPAR $\delta$ and PPAR $\gamma$ are expressed much higher in the GI track. Therefore, these two receptors likely play a role in the developmental regulation of CES2 in the GI tract [37]. While all PPARs are functionally related, they exhibit different ligand specificity [38]. An involvement of different PPARs in the developmental regulation of CES2 between the GI and liver provides an explanation to the insignificant correlation on CES2 expression between these two organs, although both organs exhibited significant age-dependent expression (Figs. 1, 2 and 3).

In contrast to RT-qPCR, Western blotting consistently detected age-related increases regardless of genes (CES2 or CYP3A4) or organs (liver and duodenum) (Figs. 1 and 3). The precise mechanisms remain to be determined on the disproportions between mRNA and protein expression of CES2 and CYP3A4. In 
particular, duodenal samples in the adult group had the lowest CYP3A4 mRNA, but the same group expressed the highest level of CYP3A4 protein (Left of Fig. 3B). It is likely that the translational efficiency of intestinal CYP3A4 mRNA increases with age. Alternatively, the expression of certain microRNAs (miRs) that target CYP3A4 transcript increases and thus negatively affects the production of CYP3A4 proteins. In support of this possibility, several miRs have been reported to regulate the expression of CYP3A4 [39] or the pregnane $\mathrm{X}$ receptor, a major regulator of CYP3A4 expression in response to xenobiotic stimuli [40]. Nevertheless, it remains to be determined whether these miRs are expressed in an age-dependent manner.

The precise pharmacological significance of the organ-specific expression remains to be established. In the case of CES2, the contribution to the overall hydrolysis between the liver and GI is likely closer than the difference in the expression. In this study, the entire wall of the small intestine was used. It is not clear whether CES2 is present in the whole section of the wall or primarily in the mucosal layer. Based on the study in the puppies [41], the mucosal layer takes $60-70 \%$ of the thickness of the entire wall. Therefore, the expression levels were probably underestimated if CES2 is exclusively present in the mucosal layer. Likewise, the presence of CES2 in the liver may not be uniform. We previously showed that several rat carboxylesterases were primarily located in the centrilobular regions $[42,43]$. Finally, the initial concentrations of drugs and other xenobiotics in the small intestine are much higher than those in the liver after oral administration. Therefore, it is likely that the GI track contributes much greater to the overall hydrolysis than the levels expression.

In summary, our work points to several important conclusions. First, the postnatal surge of mRNA expression in the liver, although exceptions may exist, is a general phenomenon among biotransformation genes. Second, high-levels of mRNA do not necessarily result in high-levels of protein, and such disproportions likely occur in an organ-specific manner. And third, individuals may disproportional drug- 
metabolizing capacities between the liver and the GI tract, two major biotransformation organs. These findings establish that developmental regulation occurs in a gene and organ-dependent manner.

\section{Footnotes}

${ }^{1}$ This work was supported by grant from Hoffmann-La Roche Inc, and the National Institutes of Health (ES07965, GM61988 and AT007705).

\section{REFERENCE}

[1] Schleidgen S, Klingler C, Bertram T, Rogowski WH, Marckmann G. What is personalized medicine: sharpening a vague term based on a systematic literature review. BMC Med Ethics. 2013;14:55.

[2] Patel L, Parker B, Yang D, Zhang W. Translational genomics in cancer research: converting profiles into personalized cancer medicine. Cancer Biol Med. 2013;10:214-20.

[3] Preissner SC, Hoffmann MF, Preissner R, Dunkel M, Gewiess A, Preissner S. Polymorphic Cytochrome P450 Enzymes (CYPs) and Their Role in Personalized Therapy. PLoS One. 2013;8:e82562.

[4] Stoll F, Burhenne J, Lausecker B, Weiss J, Thomsen T, Haefeli WE, Mikus G. Reduced exposure variability of the CYP3A substrate simvastatin by dose individualization to CYP3A activity. J Clin Pharmacol. 2013;53:1199-204.

[5] Lewis DF. Human cytochromes P450 associated with the phase 1 metabolism of drugs and other xenobiotics: a compilation of substrates and inhibitors of the CYP1, CYP2 and CYP3 families. Curr Med Chem. 2003; 10:1955-72. 
[6] Deenen MJ, Cats A, Beijnen JH, Schellens JH. Part 3: Pharmacogenetic variability in phase II anticancer drug metabolism. Oncologist. 2011; 16:992-1005.

[7] You G Towards an understanding of organic anion transporters: structure-function relationships. Med Res Rev. 2004; 24:762-74.

[8] Xie M, Yang D, Liu L, Xue B, Yan B. Rodent and human carboxylesterases: immuno-relatedness, overlapping substrate specificity, differential sensitivity to serine inhibitors, and tumor-related expression. Drug Metab Dispos. 2002; 30:541-7.

[9] Zancanella V, Giantin M, Lopparelli RM, Nebbia C, Dacasto M. Constitutive expression and phenobarbital modulation of drug metabolizing enzymes and related nuclear receptors in cattle liver and extra-hepatic tissues. Xenobiotica. 2012;42:1096-109.

[10] Pearce RE, Gotschall RR, Kearns GL, Leeder JS. Cytochrome P450 Involvement in the biotransformation of cisapride and racemic norcisapride in vitro: differential activity of individual human CYP3A isoforms. Drug Metab Dispos. 2001;29:1548-54.

[11] Zanger UM, Klein K, Thomas M, Rieger JK, Tremmel R, Kandel BA, Klein M, Magdy T. Genetics, epigenetics and regulation of drug metabolizing cytochrome P450 enzymes. Clin Pharmacol Ther. 2013; in press.

[12] Song X, Li Y, Liu J, Mukundan M, Yan B. Simultaneous substitution of phenylalaine-305 and aspartate-318 of rat PXR by the corresponding human residues abolishes the ability to transactivate the cytochrome P4503A23 promoter. J Pharmacol Exp Ther. 2005; 312:571-82. 
[13] Liu F, Yang D, Song X, Deng R, Yan B. The far and distal enhancers in the CYP3A4 gene coordinates the proximal promoter in responding to the pregnane $\mathrm{X}$ receptor similarly but differentially to hepatocyte nuclear factor-4 $\alpha$. Biochem J. 2008; 409:243-50.

[14] Hines RN. Developmental expression of drug metabolizing enzymes: impact on disposition in neonates and young children. Int J Pharm. 2013; 452:3-7.

[15] Yang D, Pearce R, Wang X, Roger Gaedigk, Wan YJY, Yan B. Human carboxylesterases HCE1 and HCE2: Ontogenic expression, inter-individual variability and differential hydrolysis of oseltamivir, aspirin, deltamethrin and permethrin. Biochem Pharmacol. 2009; 77:238-47.

[16] Morgan EW, Yan B, Greenway D, Parkinson A. Regulation of two rat liver microsomal carboxylesterase isozymes: species differences, tissue distribution and the effects of age, sex and xenobiotic treatment of rats. Arch Biochem Biophys. 1994; 315:514-26.

[17] Lu H, Gunewardena S, Cui JY, Yoo B, Zhong XB, Klaassen CD. RNA-sequencing quantification of hepatic ontogeny and tissue distribution of mRNAs of phase II enzymes in mice. Drug Metab Dispos. 2013;41:844-57.

[18] Peng L, Cui JY, Yoo B, Gunewardena SS, Lu H, Klaassen CD, Zhong XB. RNA-sequencing quantification of hepatic ontogeny of phase-I enzymes in mice. Drug Metab Dispos. 2013; 41:2175-86.

[19] Anand SS, Kim KB, Padilla S, Muralidhara S, Kim HJ, Fisher JW, Bruckner JV. Ontogeny of hepatic and plasma metabolism of deltamethrin in vitro: role in age-dependent acute neurotoxicity. Drug Metab Dispos. 2006; 34:389-97. 
[20] Sheets LP, Doherty JD, Law MW, Reiter LW, Crofton KM. Age-dependent differences in the susceptibility of rats to deltamethrin. Toxicol Appl Pharmacol. 199q4; 126:186-90.

[21] Pope CN, Chakraborti TK, Chapman ML, Farrar JD, Arthun D. Comparison of in vivo cholinesterase inhibition in neonatal and adult rats by three organophosphorothioate insecticides. Toxicology. 1991; 68:51-61.

[22] Zhu HJ, Appel DI, Jiang Y, Markowitz JS. Age- and sex-related expression and activity of carboxylesterase 1 and 2 in mouse and human liver.Drug Metab Dispos. 2009; 37:1819-25.

[23] Shi D, Yang D, Prinssen EP, Brian E. Davies BE, Yan B. Surge in expression of carboxylesterase-1 during the post-natal stage enables a rapid gain of the capacity to activate the anti-influenza prodrug oseltamivir. J Infect Dis. 2011; 203:937-42.

[24] Sanghani SP, Sanghani PC, Schiel MA, Bosron WF. Human carboxylesterases: an update on CES1, CES2 and CES3. Protein Pept Lett. 2009; 16:1207-14.

[25] Yan B (2012) Hydrolytic Enzymes. in: Zanger and Anzenbacher (eds) Metabolism of Drugs and Other Xenobiotics. WILEY-VCH Verlag GmbH \& Co. KGaA, Weinheim. pp165-199.

[26] Klein K, Zanger UM. Pharmacogenomics of Cytochrome P450 3A4: Recent Progress Toward the "Missing Heritability" Problem. Front Genet. 2013; 4:12.

[27] Paine MF, Hart HL, Ludington SS, Haining RL, Rettie AE, Zeldin DC. The human intestinal cytochrome P450 "pie". Drug Metab Dispos. 2006;34:880-6. 
[28] Fakhoury M, Litalien C, Medard Y, Cavé H, Ezzahir N, Peuchmaur M, Jacqz-Aigrain E. Localization and mRNA expression of CYP3A and P-glycoprotein in human duodenum as a function of age. Drug Metab Dispos. 2005;33:1603-7.

[29] Smith NF, Figg WD, Sparreboom A. Pharmacogenetics of irinotecan metabolism and transport: an update. Toxicol In Vitro. 2006;20:163-75.

[30] Yang J, Shi D, Yang D, Song X, Yan B (2007) Interleukin-6 suppresses the expression of carboxylesterases HCE1 and HCE2 through transcriptional repression. Mol Pharmacol. 2007; 72:686-94.

[31] Xiao D, Chen YZ, Yang D, Yan B. Age-related inducibility of carboxylesterases by the antiepileptic agent phenobarbital and implications in drug metabolism and lipid accumulation. Biochem Pharmacol. $2012 ; 84: 232-9$.

[32] Zhu W, Song L, Zhang H, Matoney L, LeCluyse E, Yan B. Dexamethasone differentially regulates expression of carboxylesterase genes in humans and rats. Drug Metab Dispos. 2000; 28:186-91.

[33] Hondares E, Rosell M, Gonzalez FJ, Giralt M, Iglesias R, Villarroya F. Hepatic FGF21 expression is induced at birth via PPARalpha in response to milk intake and contributes to thermogenic activation of neonatal brown fat. Cell Metab. 2010; 11:206-12.

[34] Hosokawa M, Hirata K, Nakata F, Suga T, Satoh T. Species differences in the induction of hepatic microsomal carboxylesterases caused by dietary exposure to di(2-ethylhexyl)phthalate, a peroxisome proliferator. Drug Metab Dispos. 1994; 22:889-94. 
[35] Poole M, Bridgers K, Alexson SE, Corton JC. Altered expression of the carboxylesterases ES-4 and ES-10 by peroxisome proliferator chemicals. Toxicology. 2001; 165:109-19.

[36] Wu MH, Yan B, Humerickhouse R, Dolan ME. Irinotecan activation by human carboxylesterases in colorectal adenocarcinoma cells. Clin Cancer Res. 2002; 8:2696-700.

[37] Auboeuf D, Rieusset J, Fajas L, Vallier P, Frering V, Riou JP, Staels B, Auwerx J, Laville M, Vidal H. Tissue distribution and quantification of the expression of mRNAs of peroxisome proliferatoractivated receptors and liver $\mathrm{X}$ receptor-alpha in humans: no alteration in adipose tissue of obese and NIDDM patients. Diabetes. 1997; 46:1319-27.

[38] Zoete V, Grosdidier A, Michielin O. Peroxisome proliferator-activated receptor structures: ligand specificity, molecular switch and interactions with regulators. Biochim Biophys Acta. 2007;1771:915-25.

[39] Pan YZ, Gao W, Yu AM. MicroRNAs regulate CYP3A4 expression via direct and indirect targeting. Drug Metab Dispos. 2009;37:2112-7.

[40] Takagi S, Nakajima M, Mohri T, Yokoi T. Post-transcriptional regulation of human pregnane X receptor by micro-RNA affects the expression of cytochrome P450 3A4. J Biol Chem. 2008; 283:967480.

[41] Stander N, Wagner WM, Goddard A, Kirberger RM. Normal canine pediatric gastrointestinal ultrasonography. Vet Radiol Ultrasound. 2010; 51:75-8.

[42] Yan B, Yang D, Brady M, Parkinson A. Rat kidney carboxylesterase: cloning, sequencing, cellular localization and relationship to liver hydrolase B. J Biol Chem. 1994; 269:29688-96. 
[43] Yan B , Yang D ,Brady M , Parkinson A. Rat testicular carboxylesterase: clonin臣, sequencln臣、 cellular localization and relationship to liver hydrolase A. A 此h Biochern Biophys. 1995; 316:899-908 
Table I. Demographic distribution of liver donors

\begin{tabular}{|c|c|c|c|c|c|}
\hline Group & $\mathrm{n}$ & Male/Female & $\mathrm{CA}$ & $\mathrm{AA}$ & $\mathrm{H}$ \\
\hline I (1-31 days) & 12 & $6 / 6$ & 6 & 4 & 2 \\
\hline II (35-70 days) & 13 & $5 / 8$ & 5 & 8 & \\
\hline III (89-119 days) & 10 & $7 / 3$ & 4 & 6 & \\
\hline IV (123-198 days) & 10 & $8 / 2$ & 4 & 5 & 1 \\
\hline$\underline{\mathrm{V}(\geq 18 \text { years }) \quad 14}$ & & & 10 & 4 & \\
\hline
\end{tabular}

Abbreviation: CA, Caucasian-American; AA, African American; H, Hispanic 
Table II. Relative levels of liver CES2 and CYP3A4 mRNA in various age groups

\begin{tabular}{lll}
\hline Group & CES2 mRNA & CYP3A4 mRNA \\
\hline I (1-31 days) & $2.07(1.57)$ & $1.33(1.79)$ \\
II (35-70 days) & $5.57(3.45)$ & $38.6(34.4)$ \\
III (89-119 days) & $6.99(2.63)$ & $65.6(101.8)$ \\
IV (123-198 days) & $6.36(1.56)$ & $58.6(75.6)$ \\
V ( $\geq 18$ years $)$ & $7.96(3.81)$ & $59.7(69.7)$ \\
\hline
\end{tabular}

Note Data presented as mean \pm SD (parenthesis) 


\section{Table I. Demographic distribution of duodenal donors}

\begin{tabular}{lcllll}
\hline Group & $\mathrm{n}$ & Male/Female & CA & AA & H \\
\hline I (1-70 days) & 11 & $3 / 8$ & 6 & 5 & \\
II (76-141 days) & 9 & $7 / 2$ & 3 & 6 & \\
III (163-332 days) & 13 & $9 / 4$ & 7 & 6 & \\
V ( $\geq 18$ years) & 10 & $5 / 5$ & 8 & 2 & \\
\hline
\end{tabular}

Abbreviation: CA, Caucasian-American; AA, African American; H, Hispanic 
Table IV. Relative levels of duodenal CES2 and CYP3A4 mRNA in various age groups

\begin{tabular}{lll}
\hline Group & CES2 mRNA & CYP3A4 mRNA \\
\hline I (1-70 days) & $2.71(2.98)$ & $19.7(35.2)$ \\
II (76-141 days) & $3.42(4.57)$ & $14.2(29.4)$ \\
III (163-332 days) & $6.33(4.23)$ & $15.3(37.7)$ \\
V ( $\geq 18$ years $)$ & $6.62(12.01)$ & $6.61(15.8)$ \\
\hline
\end{tabular}

Note Data presented as mean \pm SD (parenthesis) 


\section{LEGENDS FOR FIGURES}

Fig. 1. Hepatic expression of CES2 and CYP3A4 as a function of age Total RNAs from livers were subjected to RT-qPCR analysis for the levels of CES2 or CYP3A4 mRNA by Taqman probe as described in the section of Materials and Methods. The signals from each target were normalized based on the signal from Pol II and expressed as relative levels among all samples. The data are presented as mean \pm SD. For Western analysis S9 fractions $(7.5 \mu \mathrm{g}$ for CES2 and $10 \mu \mathrm{g}$ for CYP3A4) were resolved by $7.5 \%$ SDS-PAGE and transferred electrophoretically to nitrocellulose membranes. The samples were pooled with the same amounts of proteins from individual samples in the same group. The blots were incubated with an antibody against CES2, CYP3A4 or GAPDH and developed with chemiluminescent substrate. The signal was captured by Carestream 2200 PRO imager. *Statistical significance at $p<0.05$.

Fig. 2. Correlation analyses between age and levels of CES2 or CYP3A4 mRNA The correlation was performed with SPSS Statistics 20. (A) Correlation of CES2 mRNA as a function of age:1-198 days (Left) or 1-70 days (Right). (B) Correlation of CYP3A4 mRNA as a function of age:1-198 days (Left) or 1-70 days (Right). (C) Correlation of CES2 over CYP3A4 mRNA as a function of age:1-198 days (Left) or 1-70 days (Right). Correlation coefficients and corresponding $p$ values are shown.

Fig. 3. Duodenal expression of CES2 and CYP3A4 as a function of age and correlation analyses (A) Duodenal expression of CES2 Total RNAs from duodena were subjected to RT-qPCR analysis for the levels of CES2 mRNA by Taqman probe and the signals from each target were normalized based on the signal from Pol II and expressed as relative levels among all samples. The data are presented as mean \pm SD. For Western analysis S9 fractions $(10 \mu \mathrm{g})$ were resolved by $7.5 \%$ SDS-PAGE and transferred electrophoretically to nitrocellulose membranes. The blot was stained by $0.1 \%$ Ponceau $\mathrm{S}$ as described in the section of Materials and Methods. Thereafter the blot was incubated with an antibody against CES2 or GAPDH and developed with chemiluminescent substrate. The signal was captured by Carestream 
2200 PRO imager. Once again, the correlation of CES2 mRNA as a function of age was performed with SPSS Statistics 20. (B) Duodenal expression of CYP3A4 All procedures for the expression and correlation analysis for CYP3A4 were the same as described above. However, the Western blotting used $20 \mu \mathrm{g}$ of $\mathrm{S} 9$ fractions. *Statistical significance at $p<0.05$.

Fig. 4. Multi-sampling study on the expression of CES2 Liver, duodenal and jejunal S9 fractions (8 $\mu \mathrm{g})$ were resolved by $7.5 \%$ SDS-PAGE and transferred electrophoretically to nitrocellulose membranes. The blots were stained by $0.1 \%$ Ponceau $\mathrm{S}$ and then incubated with an antibody against CES2 or GAPDH and developed with chemiluminescent substrate. The signal was captured by Carestream 2200 PRO imager. Once again, the correlation of CES2 mRNA between duodenum and jejunum (Left) or liver jejunum was performed (Right) with SPSS Statistics 20. Correlation coefficients and corresponding $p$ values are shown. 

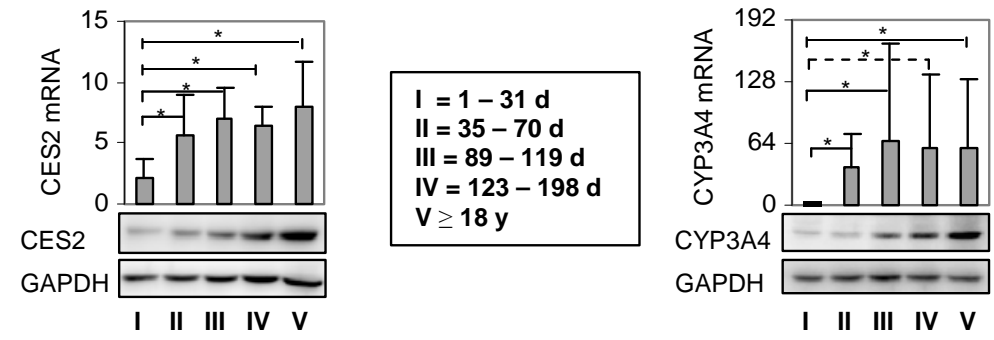

Fig. 1 (Chen etal., 2014) 
A
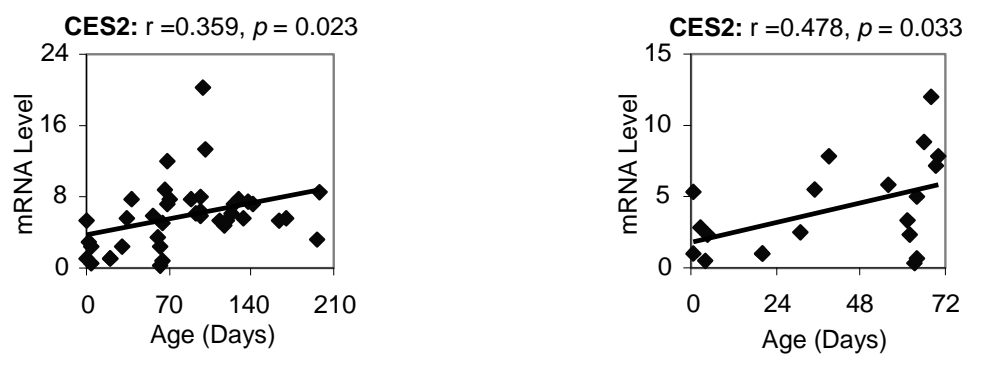

B
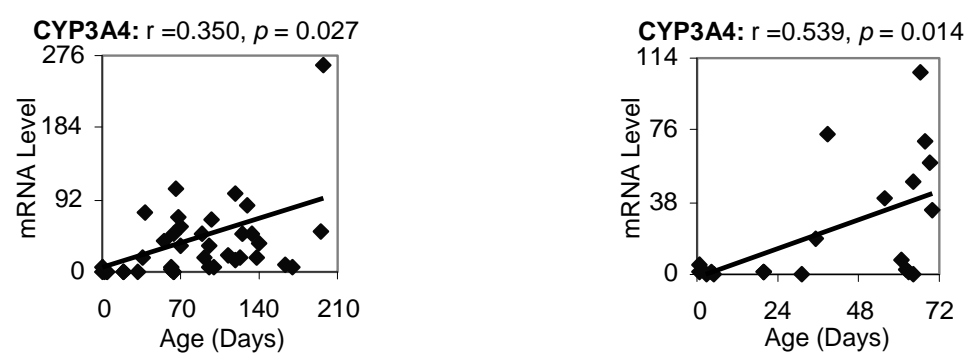

C

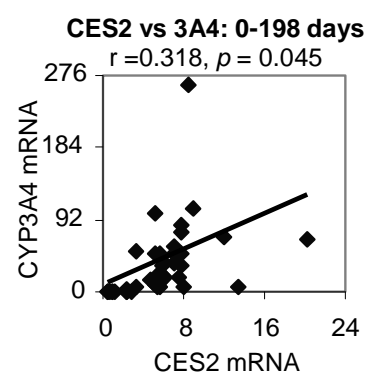

Fig. 2 (Chen etal., 2014) 
A
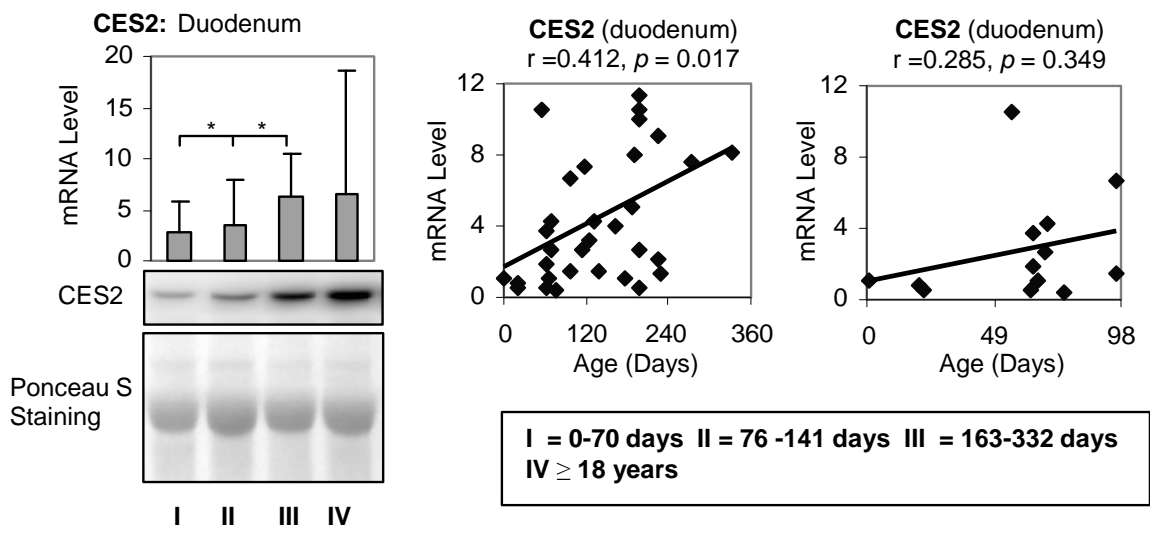

I = 0-70 days II = $76-141$ days III = 163-332 days IV $\geq 18$ years

B
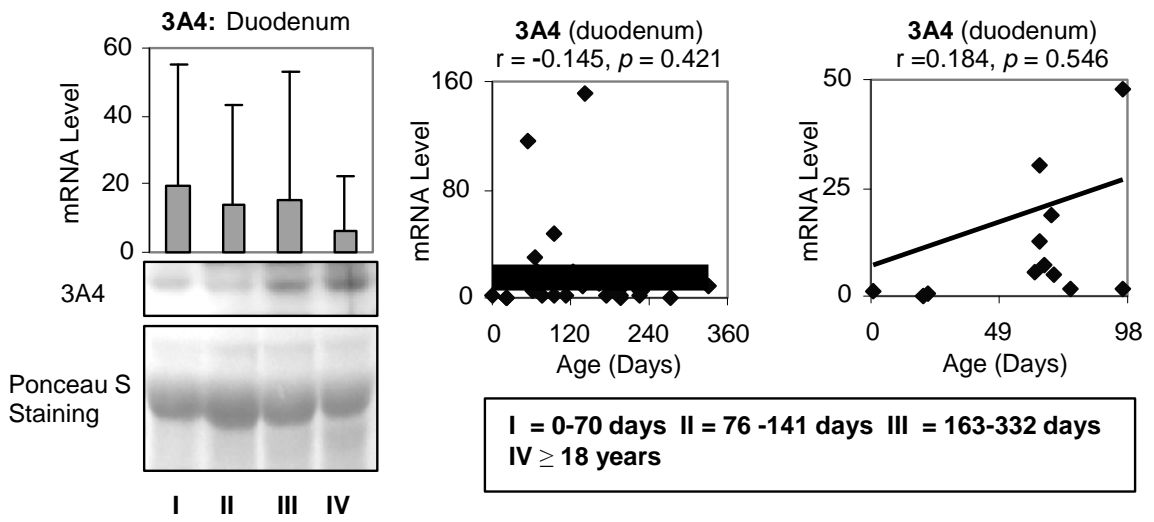

$\mathrm{I}=0-70$ days $\mathrm{II}=76-141$ days $\mathrm{III}=163-332$ days IV $\geq 18$ years

Fig. 3 (Chen etal., 2014) 
A

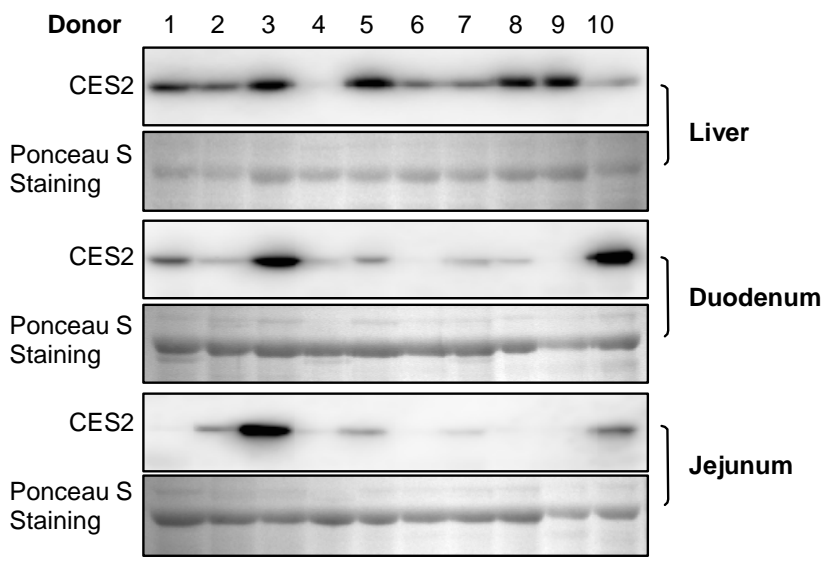

B
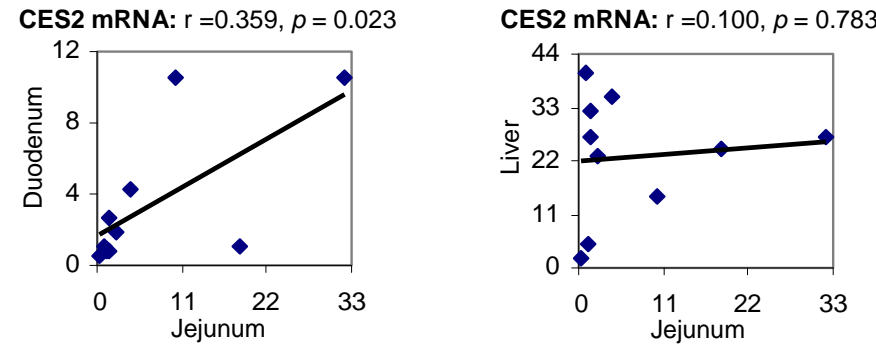

Fig. 4 (Chen etal., 2014) 


\title{
Original Research
}

\section{ANTIOXIDANT SULFORAPHANE AND SENSITIZER TRINITROBENZENE SULFONATE INDUCE CARBOXYLESTERASE-1 THROUGH AN INVERSE ELEMENT TRANSACTIVATED BY NUCLEAR FACTOR-E2 RELATED FACTOR-2}

\author{
Yi-Tzai Chen, Deshi Shi, Dongfang Yang and Bingfang Yan \\ Department of Biomedical Sciences \\ Center for Pharmacogenomics and Molecular Therapy \\ University of Rhode Island \\ Kingston, RI 02881
}

(published by Chen, Y. T., Shi, D., Yang, D., \& Yan, B. (2012). Biochem Pharmacol)

Running Title: $\quad$ CES1 targeted by both antioxidant and sensitizer via Nrf2

Address Correspondence to: Dr. Bingfang Yan

Department of Biomedical and Pharmaceutical Sciences University of Rhode Island

Kingston, RI 02881

Phone: (401) 874-5032

Fax: (401) 874-5048

E-mail: byan@uri.edu

\author{
Word count \\ Reference numbers \\ Greyscale illustrations $\quad 7$ \\ Color illustrations $\quad 0$
}




\begin{abstract}
Aims Carboxylesterase-1 (CES1), the most versatile human carboxylesterase, plays critical roles in drug metabolism and lipid mobilization. This enzyme is highly induced by antioxidants and sensitizers. These compounds are known to activate nuclear factor-E2 related factor-2 (Nrf2) by reacting to kelch-like ECH-associated protein-1 (Keap1). The aims of this study were to determine whether antioxidant sulforaphane (SFN) and sensitizer trinitrobenzene sulfonate (TNBS) target Keap1 similarly and whether they use the same element for CES1 induction.

Results Two elements (S/ARE and ARE4) were identified to support Nrf2 in the regulated expression of CES1A1. Both elements were bound by Nrf2, however, the S/ARE element supported whereas the ARE4 element repressed the transactivation of Nrf2. The repression required higher amounts of Nrf2. SFN promoted intramolecular oxidation whereas TNBS promoted intermolecular oxidation of Keap1.

Innovation This study reports an Nrf2 repressive element although this transcription factor generally confers transactivation activity. SFN and TNBS, both activating the Keap1-Nrf2 pathway, react differently to Keap1.

Conclusion Both positive and negative Nrf2 elements exist even within the same gene. Common activators of Nrf2 may differ in the molecular recognition of Keap1. High levels of CES1 are linked to lipid retention. Excessive induction of CES1 by antioxidants and sensitizers likely provides a mechanism for potential detrimental effect on human health.
\end{abstract}




\section{INTRODUCTION}

Carboxylesterases (CES, E.C.3.1.1.1) constitute a large class of enzymes that play important roles in drug metabolism and lipid mobilization [1-4]. In the human genome, seven carboxylesterase genes are identified [1]. However, only three are catalytically characterized including CES1, CES2 and CES3 [5]. CES1 is encoded by two distinct genes: CES1A1 and CES1A2 [1], but CES1A1 is normally expressed to a greater extent [6]. CES1 is the most versatile human carboxylesterase and catalyzes hydrolytic, synthetic and transactivation reactions. While all carboxylesterases are found to play roles in drug metabolism, emerging evidence links the sustained high-level expression of CES1 to the increased risk of developing cardiovascular diseases, obesity and insulin resistance [7-9].

Antioxidants and skin sensitizers are two types of compounds recently shown to induce CES1 [10-13]. Some sensitizers induced CES1 by as many as 20 fold [111]. The precise mechanism on the sensitizer-induction remains to be established. The induction of CES1 by antioxidants, on the other hand, is mediated by Nrf2 (nuclear factor-E2 related factor-2) [14]. This transcription factor recognizes antioxidant response element (ARE) and confers potent transactivation [15]. RNA interference against Nrf2 abolished CES1 induction by antioxidants [14]. However, a native promoter reporter containing putative AREs was repressed by Nrf2 [14]. Majority of skin sensitizers, on the other hand, are sulfhydryl reactive agents and shown to react with kelch-like ECH-associated protein-1 (Keap1) [10, 13], an inhibitor of Nrf2. Interaction with Keap1 by sensitizers leads to Nrf2 activation. The magnitude of the activation was correlated with their sensitizing potency [10].

The present study was performed to test the hypothesis that both antioxidants and sensitizers react to Keap1 and causes transactivation of CES1A1 via a novel Nrf2 element. To test this 
hypothesis, Keap1-transfected cells were treated with sensitizer trinitrobenzene sulfonate (TNBS) or antioxidant DL-sulforaphane (SFN) and various molecular species of Keap1 were determined. In contrary to the hypothesis, SFN promoted intramolecular oxidation whereas TNBS promoted intermolecular oxidation of Keap1. To locate the element supporting the transactivation, the regulatory sequence of the CES1A1 gene was dissected and tested for the responsiveness to TNBS, SFN or Nrf2. Two elements were identified and designated as S/ARE (sensitizing/antioxidant response element) and ARE4, respectively. Interestingly, the S/ARE element supported Nrf2 transactivation whereas the ARE4 repressed it although the S/ARE element was a more sensitive target of Nrf2. 


\section{RESULTS}

\section{CES1 induction by SFN and TNBS in primary cultures and cell lines}

Humans are exposed to antioxidants and sensitizers primarily through the gastrointestinal track and skin. We first confirmed whether CES1 is induced by SFN and TNBS in primary cultures and cell lines from these organs. Cells were treated with SFN or TNBS and CES1 expression was determined initially by RT-qPCR with a Taqman probe. This probe recognizes both

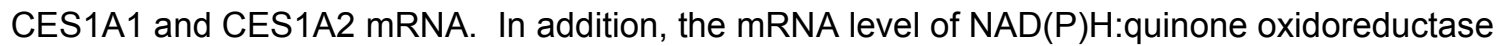
(NQO1), an Nrf2 target gene [16], was determined as well. As summarized in Fig. 1, both SFN and TNBS significantly increased CES1 and NQO1 mRNA. The highest induction of CES1 mRNA was 3.9 fold and occurred in Huh7 cells treated with SFN (Fig. 1D) and the least (1.6 fold) in primary hepatocytes treated with TNBS (Fig. 1C). In contrast, the highest induction of NQO1 mRNA was 5.7 fold and occurred in primary hepatocytes (Fig. 1C), the least (1.9 fold) in primary fibroblasts treated with SFN (Fig. 1A). Except for HT1080 cells, SFN caused greater induction of CES1 than TNBS, and NQO1 mRNA was induced to a greater or comparable extent by TNBS (Fig. 1). In HT1080 cells, TNBS caused slightly higher induction of CES1 mRNA than SFN but the opposite was true on NQO1 induction (Fig. 1B). Both SFN and TNBS markedly increased CES1 protein (Fig. 1E).

\section{Stimulation of the CES1A1 promoter by SFN, TNBS and Nrf2}

Nrf2 was implicated in the induction of CES1A1 by antioxidants including SFN [14], and many sensitizers are potent activators of Nrf2 [13]. We next tested whether TNBS and SFN induce CES1A1 via the same Nrf2 element. Reporters were prepared to contain the CES1A1 promoter and upstream sequence at varying length. As shown in Fig. 2A (Middle), reporters containing upstream sequence of 3582 bp (i.e., -3582) or further responded to both SFN and TNBS. The CES1A1-3582-Luc reporter was activated the most (Fig. 2A). In contrast, the other reporters, containing shorter sequence than the CES1A1-3582-Luc reporter, were suppressed by both 
chemicals, and the suppression was greater on CES1A1-3432-Luc and CES1A1-2293-Luc than CES1A1-1426-Luc (Middle of Fig. 2A).

Next we tested whether these reporters show a similar pattern of response to Nrf2. Huh7 cells were transfected with a reporter, along with Nrf2 or the vector. Consistent with the results on the TNBS and SFN treatment, the sequence from -3582 to -3432 was identified to support Nrf2transactivation (Fig. 2A, Right). Likewise, the CES1A1-3432-Luc and CES1A1-2293-Luc reporters were repressed by Nrf2 (Right of Fig. 2A). To further narrow down the sequence supporting the action of Nrf2, deletions of the CES1A1-3582-Luc reporter were made from the 5' end and the resultant reporters were tested for the lost responsiveness to Nrf2. As shown in Fig. 2B, the reporter 1A1-3492-Luc but not 1A1-3482-Luc was transactivated by Nrf2. Actually, the 1A1-3482-Luc reporter was repressed by Nrf2. These findings suggest that the 10-base sequence from -3492 to -3482 was critical for Nrf2-transactivation.

\section{Characterization of the SIARE element}

The study with deletion mutants suggested that this 10-base sequence contains or is part of the Nrf2/TNBS/SFN response element: designated the S/ARE element. We next performed a set of experiments to characterize this element. We first tested whether Nrf2 binds S/ARE element and whether this binding can be competed by ARE4, an element previously identified to support Nrf2-transactivation [14]. As shown in Fig. 3A, incubation of a biotin-labeled S/ARE probe with nuclear extracts from SFN-treated cells produced a shifted band (lane 2). This band was eliminated by an Nrf2 antibody (lane 3) and competed by non-labeled S/ARE (lanes 4 and 5), but not its mutant (lanes 6 and 7). In addition, non-labeled ARE4 element effectively competed the binding as well (lanes 8 and 9). Nevertheless, this experiment demonstrated that both the S/ARE and ARE4 were bound by Nrf2. We next tested whether the S/ARE-containing sequence is intracellularly occupied by Nrf2. ChIP analysis was performed with an Nrf2 
antibody and the precipitated DNA was detected for the enriched S/ARE- or ARE4-fragment. As shown in Fig. 3B, comparable amplifications were detected with the input on both S/AREand ARE4-fragments, however, the ChIPed DNA produced robust amplification of the S/AREbut not ARE4- fragment (Fig. 3B). As expected, no amplification was detected with sample precipitated with pre-immune IgG.

\section{Activation of the SIARE element reporter by SFN, TNBS and Nrf2}

The EMSA and ChIP experiments demonstrated that the S/ARE element serves as a major site for Nrf2 to interact with the CES1A1 gene. We next tested whether the interaction confers biological activities. Three reporters were tested including the S/ARE, CES1A1-3582-Luc and CES1A1-3582m-Luc reporters (Fig. 4A). The CES1A1-3582m-Luc, a mutant of the CES1A13582-Luc, had the S/ARE element replaced with its mutant sequence (Table I). Cotransfection was performed to test the responsiveness of these reporters to SFN, TNBS and Nrf2. As shown in Fig. 4B, SFN at $0.5 \mu \mathrm{M}$ significantly activated the S/ARE reporter and the CES1A1-3582-Luc (bars labeled with different letters). Higher concentrations caused higher activation of both reporters except $10 \mu \mathrm{M}$ on the S/ARE reporter (Fig. 4B). In contrast, none of the concentrations activated the CES1A1-3582m-Luc reporter. Actually this mutant reporter was suppressed somewhat, although the suppression did not reach the level of statistical significance (Fig. 4B). Similar responding patterns to TNBS were detected (Fig. 4C). Likewise, Nrf2 increased the activities of S/ARE and CES1A1-3582-Luc but not CES1A1-3582m-Luc reporter (Fig. 4D). However, several notable differences were observed (Fig. 4D): (a) Nrf2 caused slightly less activation of the CES1A1-3582-Luc than the S/ARE reporter, when Nrf2 was assayed at 1-10 ng; (b) Nrf2 at $20 \mathrm{ng}$, the highest concentration used, caused less activation of both reporters; and

(c) it was surprising that higher amounts of Nrf2 (10 and $20 \mathrm{ng}$ ) significantly repressed the mutant reporter CES1A1-3582m-Luc (Fig. 4D). 


\section{Activation comparison of SIARE element with other Nrf2 elements}

The EMSA, ChIP and reporter experiments established that the S/ARE element supported robust responsiveness to SFN, TNBS and Nrf2. Next, we compared the responding potential of this element with well-characterized Nrf2 elements. Reporters harboring the CES1A1-ARE4 element or the corresponding CES1A2-S/ARE were also included. In addition to Nrf2, these reporters were tested for their responsiveness to Nrf1, an Nrf2 functionally related protein [17]. For direct comparison, reporters were prepared to contain a single copy of an ARE element. As shown in Fig. 5, all reporters were transactivated by Nrf1 and Nrf2 except Nrf1 on the NQO1 reporter (Fig. 5F) and Nrf2 on the 1A1-ARE4 reporter (Fig. 5B). In both cases, their activity was actually decreased, and the decrease was statistically significant in the 1A1-ARE4 reporter (Fig. 5B). With a single exception (i.e., 1A1-ARE4), Nrf2 caused greater activation than Nrf1 on all reporters tested. The highest transactivation was detected with the CES1A1-S/ARE reporter (5.8 fold) followed by the CES1A2-S/ARE reporter (5.2 fold). The CES1A2-S/ARE reporter (Figs. 5A and C), compared with its CES1A2-S/ARE counterpart, was activated to a greater extent by Nrf1. In some other cases such as the reporter of GCLM (glutamate-cysteine ligase regulatory subunit), Nrf1 and Nrf2 caused comparable activation (Fig. 5E).

\section{Differential reactivity of SFN and TNBS toward Keap1}

In the Keap1-Nrf2 pathway, Keap1 is the initiator whereas Nrf2 is the executor. Keap1 is a cysteine-rich protein and some of the cysteines serve as reactive targets for antioxidants and sensitizers. As a result, Keap1 has three forms depending on the oxidative status of cysteines: reduced Keap1, intramolecular and intermolecular Keap1. We took advantage of their differences in electrophoretic mobility and tested whether SFN and TNBS produce similar composition of these three Keap1 molecular species. Cells were transfected with Keap1 and treated with SFN or TNBS at various concentrations and the cell lysates were then separated by non-reducing electrophoresis followed by Western blotting. As shown in Fig. 6A, both SFN and 
TNBS decreased reduced mouse Keap1. Surprisingly they differed in increasing intramolecular and intermolecular Keap1. SFN increased intramolecular Keap1 whereas TNBS increased intermolecular Keap1. Similar changes were detected with human Keap1 (Fig. 5B). 


\section{DISCUSSION}

CES1 is the most versatile human carboxylesterase and catalyzes hydrolysis, synthesis and transesterification [1, 2]. In this study, we reports that TNBS and SFN efficaciously induced CES1 through Nrf2. Two elements, S/ARE and ARE4, were identified to bind to Nrf2 (Fig. 3A), however, they exhibited opposite activities. S/ARE supported transactivation whereas ARE4 supported repression of Nrf2, although S/ARE was a more sensitive target (Figs. 4D and 5B). Actually, the S/ARE reporter was activated the most by Nrf2 among all ARE reporters (Fig. 5). Compared with all AREs, ARE4 differs by two nucleotides at the $4^{\text {th }}$ and $5^{\text {th }}$ position in the coresequence (Fig. 5H). The ARE4 has GA whereas other AREs have CT in these positions. However, a frequency matrix analysis has predicted that $18 \%$ of ARE elements have a $G$ and $6 \%$ an A in the $4^{\text {th }}$ and $5^{\text {th }}$ position, respectively [18], suggesting that this dinucleotide substitution (i.e., $\mathrm{CT} \rightarrow \mathrm{GA}$ ) may not be entirely responsible for the observed repression by Nrf2 (Fig. 5B).

It is likely that this $\mathrm{GA} \rightarrow \mathrm{CT}$ substitution works with flanking nucleotides and negatively responds to Nrf2. Indeed, computer program ALGGEN-PROMO predicts that the ARE4 core-sequence overlaps with a Yin-Yang1 (YY1) element. This element, CGTGAGACA, consists of 5' flanking dinucleotide CG and seven nucleotides of the ARE4 core sequence (in italic) including the dinucleotide GA discussed above (Fig. 6). Importantly, a recent study has shown that Nrf2 negatively regulated the transcription of the fibrosis transmembrane conductance receptor gene (CFTR) through an YY1 element overlapped with an ARE (CAAATGACA underlined) [19]. Although the CES1A1 YY1 element shares five nucleotides with the CFTR YY1 element, the CES1A1 YY1 element lacks the typical core nucleotides of YY1 element [19]. However, these authors detected YY1-Nrf2 complex [19], suggesting that YY1 and Nrf2 form heterodimers and bind to an YY1-Nrf2 composite site. On the other hand, Nrf2 has been established to preferably form heterodimers with small Maf proteins and confer transactivation activity [20, 21], thus 
dominating the repression through the YY1-Nrf2 mechanism [Fig. 6]. In support of this notion, the repression of CES1A1 reporters was evident when Nrf2 was highly expressed (Fig. 2A), or in the absence of the S/ARE element (Figs. 3D and 5B). Nevertheless, a confirmation of YY1, along with Nrf2, in the suppression of CES1 will provide an example of how a very same gene can be regulated by the same transcription factor with opposite regulatory activity.

Another interesting finding is that SFN and TNBS caused different changes in the overall conformation of Keap1. SFN promoted thiol oxidation of Keap1 within Keap1 whereas TNBS promoted the thiol oxidation between two Keap1 molecules (Fig. 5). Thus, TNBS induced the formation of large Keap1 complex. The precise mechanism on the difference remains to be determined. It is likely that TNBS activates the Keap1-Nrf2 pathway by directly reacting sulfhydryl groups of Keap1, whereas SFN activates it by altering the cellular oxidative potentials. In support of this possibility, TNBS but not SFN is potent sulfhydryl agent [22, 23]. However, it remains to be determined whether the different reactivity between SFN and TNBS represents general difference between antioxidants and skin sensitizers. Nevertheless, majority of skin sensitizers are sulfhydryl reactive agents $[10,13]$.

The significance of the induction of CES1 through the Nrf2 pathway remains to be determined. Carboxylesterases are generally considered detoxification enzymes, therefore, induction of CES1 likely represents cytoprotective response [1. 5]. On the other hand, induction of CES1 may have pharmacological significance, particularly regarding the metabolism of ester drugs. For example, the antiplatelet agent clopidogrel undergoes predominant hydrolysis (95\%) and hydrolysis represents inactivation [2]. As a result, exposure to antioxidants or skin sensitizers may decrease the antiplatelet activity of clopidogrel. In contrast, hydrolysis of oseltamivir, a widely used anti-influenza agent, represents activation, and only the hydrolytic metabolite exerts anti-influenza activity [24]. Therefore, induction of CES1 likely leads to increased anti-viral 
activity of oseltamivir. We have shown that the hydrolytic metabolite, compared with the parent compound oseltamivir, is more cytotoxic [24]. However, the Nrf2-mediated induction of CES1 may cause little changes in the overall toxicity as this pathway has also been found to support the induction of multidrug resistance protein-4 [25], a transporter that effluxes the hydrolytic metabolite [26].

In addition to the pharmacological implications, induction of CES1 may have pathophysiological significance as well. CES1 hydrolyzes many endogenous compounds such as triglycerides and cholesterol esters [1, 4, 5]. Hydrolysis of cholesterol esters increases free cholesterol, leading to increased synthesis of bile acids [4]. Secretion of bile acids represents the only net elimination of excessive cholesterol [27]. On the other hand, increased free fatty acids by hydrolyzing triglycerides and cholesterol esters likely increase the synthesis and secretion of very low density lipoprotein (VLDL), a precursor that leads to the formation of low density lipoprotein (LDL) (28-30). Indeed, high CES1 activity has been shown to facilitate VLDL maturation [29]. Transgenic expression of CES1 leads to increased secretion of apoB proteins and plasma triglycerides [28]. Elevated level of LDL increases the risk of developing atherosclerosis [31]. Therefore, excessive induction of CES1 without enhancing bile acid synthesis likely has detrimental effect. 


\section{INNOVATION}

Nuclear translocation of Nrf2 is the essential event in the activation of the Keap1-Nrf2 pathway [32-34]. Normally, Nrf2 is sequestered in the cytoplasm by complexing with Keap1. The presence of antioxidants or sensitizers induce conformational changes of Keap1, leading to the release and nuclear translocation of Nrf2. In this study, we have shown that both antioxidant and sensitizer activated this pathway but differed in inducing conformational changes of Keap1. SFN promoted the formation of intramolecular disulfide bonds whereas TNBS promoted the formation of intramolecular disulfide bonds of Keap1. Another innovative finding of this study is the identification of ARE4 to support Nrf2 repression, given the fact that Nrf2 is generally considered to confer transactivation activity. Interestingly, Nrf1, commonly referred as to functionally related to Nrf2 [17], exhibited opposite activity toward the ARE4 reporter, pointing to an important difference in their molecular recognition. Finally, we have shown that the S/ARE element was activated the most among several well-established Nrf2 elements. 


\section{MATERIALS AND METHODS}

Hanks balanced salt solution, TNBS and William's medium E (WME) were purchased from Sigma (St. Louis, MO). SFN was purchased from Alexis (San Diego, CA). Dulbecco's Modified Eagles Medium (DMEM), high fidelity Platinum Taq DNA polymerase, insulin-transferrinselenium (ITS) G supplement were purchased from Invitrogen (Carlsbad, CA). Dual-Luciferase Reporter Assay System was from Promega (Madison, WI). Fetal bovine serum (FBS) was from HyClone laboratories (Logan, UT). The antibody against glyceradehyde-3-phosphate dehydrogenase (GAPDH) was from Abcam (Cambridge, UK), and the antibody against Nrf2 (C-20) was from Santa Cruz Biotechnology (Santa Cruz, CA). The goat anti-rabbit IgG conjugated with horseradish peroxidase was from Pierce (Rockford, IL). Plated human primary hepatocytes were obtained from the Liver Tissues Procurement and Distribution System (University of Minnesota) or CellzDirect (Pittsboro, NC). Human dermal fibroblasts (cryopreserved) were purchased from Cascade Biologics (Portland, OR). Unless otherwise specified, all other reagents were purchased from Fisher Scientific (Fair Lawn, NJ).

\section{$\underline{\text { Reporter constructs and cotransfection assays }}$}

CES1A1 promoter reporters were prepared to contain various lengths of CES1A1 genomic sequence. All promoter reporters were subcloned from the CES1A1-6560-Luc reporter. This reporter was prepared by inserting the genomic fragment from -6560 to -21 (relatively to the translation initiation codon) into the pGL3 basic vector through Mlu I and Xho I sites. All cloning and subcloning were performed by PCR with high fidelity Platinum Taq DNA polymerase. To prepare the CES1A1-3582m-Luc reporter, site-directed mutagenesis was performed as described previously [35]. Complementary oligonucleotides (5'-CTCACCCATCACAATG $\underline{\text { AAC- }}$ IGAGGAATCATGAAGCAGAAA-3') were synthesized to introduce substitutions (underlined). The primers were annealed to the CES1A1-3582-Luc reporter and subjected to a thermocycler for a total of 15 cycles. The resultant PCR-amplified constructs were then digested with Dpn I to 
remove the non-mutated parent construct. The mutated PCR-amplified constructs were used to transform XL1-Blue bacteria. To prepare element reporters, oligonucleotides (Table I) were synthesized, annealed and ligated into the pGL3 promoter vector through Nhe I and Xho I. All reporter constructs were subjected to sequence analysis. To determine the reporter activities, cotransfection in Huh7 cells was performed. Transfection mixtures contained $100 \mathrm{ng}$ of a reporter plasmid and $0.2 \mathrm{ng}$ of CMV-Renilla luciferase plasmid. In some cases, Nrf1 and Nrf2 constructs were included. Nrf1 construct was a gift of Dr. Jefferson Y. Chan of University of California Irvine whereas Nrf2 construct was purchased from OriGene (Rockville, MD). The corresponding vector was used to equalize the total amount of plasmid DNA. Typically, cells were transfected for $12 \mathrm{~h}$ and the medium was replaced with fresh medium supplemented with $1 \%$ FBS. The treatment lasted for $24 \mathrm{~h}$ and the cells were washed once with phosphate buffered saline and collected by scraping. The reporter enzyme activities were assayed with a Dual-Luciferase Reporter Assay System as described previously.

\section{Electrophoretic mobility shift assay (EMSA)}

The EMSA experiment was performed as described previously [36]. Nuclear extracts of Huh7 cells treated with SFN $(10 \mu \mathrm{M})$ for $24 \mathrm{~h}$ were prepared with the nuclear and cytoplasmic extraction kit (Pierce, Rockford, IL). The sense and antisense oligonucleotides (Table I) were annealed by heating at $94^{\circ} \mathrm{C}$ for $5 \mathrm{~min}$ followed by gradually cooling to room temperature. The sense strand was synthesized as labeled or non-labeled form (for competition). Nuclear protein $(5 \mu \mathrm{g})$ was incubated with a double-stranded biotinylated probe $(0.1 \mathrm{pmol})$ at room temperature for $20 \mathrm{~min}$. In competition assays, nuclear extracts were first incubated with an unlabeled probe at a $25 \mathrm{x}$ or $100 \mathrm{x}$ excess for $5 \mathrm{~min}$ before addition of the labeled probe. For antibody-disruption assay, the nuclear extracts were first incubated with an antibody against Nrf2 (C-20) on ice for $20 \mathrm{~min}$ and then with the labeled probe. The protein-DNA complexes were resolved by nondenaturing polyacrylamide gel electrophoresis $(5 \%)$ and transferred onto a Biodyne $₫$ nylon 
membrane. The biotinylated probe was detected with streptavidin-conjugated horseradish peroxidase and chemiluminescent substrate (PIERCE, Rockford, IL). The chemiluminescent signal was captured by KODAK Image Station 2000, and the relative intensities were quantified by KODAK 1D Image Analysis Software (KODAK Molecular Imaging Software, Version 4.0, Rochester, NY).

\section{$\underline{\text { Chromatin immunoprecipitation (ChIP) }}$}

ChIP experiment was performed, essentially described previously [36, 37]. Huh7 Cells were treated with SFN $(10 \mu \mathrm{M})$ for $24 \mathrm{~h}$, washed and underwent cross-linking for 15 min by $1.0 \%$ formaldehyde at room temperature, and the cross-linking was terminated with glycine (final concentration of $125 \mathrm{mM}$ ). The soluble chromatins were prepared as described previously [36]. For ChIP experiment, chromatins were pre-cleared for $2 \mathrm{~h}$ at $4^{\circ} \mathrm{C}$ with protein $\mathrm{G}$ beads pretreated with herring sperm DNA $(0.2 \mathrm{mg} / \mathrm{ml})$ and BSA $(0.5 \mathrm{mg} / \mathrm{ml})$. A fraction of the pre-cleared chromatins was stored at $-80^{\circ} \mathrm{C}$ for later use as an input. An antibody against Nrf2 was added into the pre-cleared chromatins, and an overnight incubation at $4^{\circ} \mathrm{C}$ was performed. As a negative control, incubation was performed with pre-immune IgG. The antibody-bound chromatins and DNA input were analyzed by PCR for the presence of the genomic fragments containing the Nrf2-bound element with primers shown in Table I. The PCR was performed with Platinum Taq DNA polymerase for a total of 32 cycles at $94^{\circ} \mathrm{C}$ for $30 \mathrm{~s}, 58^{\circ} \mathrm{C}$ for $30 \mathrm{~s}$ and $68^{\circ} \mathrm{C}$ for $60 \mathrm{~s}$. A 3-min initial denaturation was performed.

Other analyses Protein concentrations were determined with BCA assay (Pierce) based on albumin standard. Western analysis and the preparation of anti-CES1 antibody were described elsewhere (37-39). RT-qPCR with Taqman probes was performed as described previously [40]. The Taqman probe identification numbers were: Hs00275607_m1 for CES1, Hs00168547_m1 for NAD(P)H:quinine oxidoreductase 1 (NQO1), 4352934E for GAPDH and Hs00172187_m1 for 
RNA polymerase II. Data are presented as mean \pm SD of at least three separate experiments, except where results of blots are shown in which case a representative experiment is depicted in the figures. All data were analyzed for statistical significance with PASW Statistics 18. Significant differences were made according to One-way ANOVA followed by a DUNCAN's multiple comparison test $(p<0.05)$. Bars assigned different letters indicate statistical significance among data-points. 


\title{
ACKNOWLEDGMENT
}

We thank Dr. Jefferson Y. Chan of University of California Irvine the Nrf1 construct. This work was supported by NIH grants R01GM61988 and R01ES07965.

\section{STATEMENT OF CONFLICTS OF INTEREST}

The authors indicate no potential conflict of interest.

\begin{abstract}
ABBREVIATIONS
AKR1C2, aldo-keto reductase-1C2; ARE, antioxidant response element; CES, carboxylesterase; ChIP, chromatin-immunoprecipitation; CYP, cytochrome P450; DMEM, Dulbecco's Modified Eagles Medium; EMSA, electrophoretic mobility shift assay; FBS, fetal bovine serum; GAPDH, glyceradehyde-3-phosphate dehydrogenase; GCLC, glutamate-cysteine ligase catalytic subunit; GCLM, glutamate-cysteine ligase regulatory subunit; $\mathrm{NQO}, \mathrm{NAD}(\mathrm{P}) \mathrm{H}$ :quinone oxidoreductase; Nrf2, Nuclear factor-E 2 related factor-2; PBS, phosphate buffered saline; qRT-PCR, quantitative reverse transcription-polymerase chain reaction; S/ARE, sensitizing/antioxidant response element; SFN, sulforaphane; TNBS: trinitrobenzene sulfonate; WME, William's medium $\mathrm{E}$.
\end{abstract}




\section{REFERENCE}

[1] Holmes, R.; Wright, M.; Laulederkind, S.; Cox, L.; Hosokawa, M.; Imai, T.; Ishibashi, S.; Lehner, R.; Miyazaki, M.; Potter, P.; Redinbo, M.; Robert, J.; Satoh, T.; Yamashita, T.; Yan, B.; Yokoi, T.; Rudolf-Zechner, R.; Maltais, L. Recommended Nomenclature for Five Mammalian Carboxylesterase Gene Families: Human, Mouse and Rat Genes and Proteins. Mammalian Genome. 21:427-441; 2010.

[2] Tang, M.; Mukundan, M.; Yang, J.; Charpentier, N.; LeCluyse, E.L.; Black, C.; Yang, D.; Shi, D.; Yan, B. Antiplatelet agents aspirin and clopidogrel are hydrolyzed by distinct carboxylesterases, and clopidogrel is transesterificated in the presence of ethyl alcohol. $\mathrm{J}$ Pharmacol Exp Ther. 319:1467-1476; 2006.

[3] Wei, E.; Ben Ali, Y.; Lyon, J.; Wang, H.; Nelson, R.; Dolinsky, V.W.; Dyck, J.R.; Mitchell, G.; Korbutt, G.S.; Lehner, R. Loss of TGH/Ces3 in mice decreases blood lipids, improves glucose tolerance, and increases energy expenditure. Cell Metab. 11:183-193; 2010.

[4] Zhao, B.; Natarajan, R.; Ghosh, S. Human liver cholesteryl ester hydrolase: cloning, molecular characterization, and role in cellular cholesterol homeostasis. Physiol Genomics. 23:304-310; 2005.

[5] Sanghani, S.P.; Sanghani, P.C.; Schiel, M.A.; Bosron, W.F. Human carboxylesterases: an update on CES1, CES2 and CES3. Protein Pept Lett. 16:1207-1214; 2009.

[6] Hosokawa, M.; Furihata, T.; Yaginuma, Y.; Yamamoto, N.; Watanabe, N.; Tsukada, E.; Ohhata, Y.; Kobayashi, K.; Satoh, T.; Chiba, K. Structural organization and characterization of 
the regulatory element of the human carboxylesterase (CES1A1 and CES1A2) genes. Drug Metab Pharmacokinet. 23:73-84; 2008.

[7] MacLaren, R.E.; Cui, W.; Lu, H.; Simard, S.; Cianflone, K. (2010) Association of adipocyte genes with ASP expression: a microarray analysis of subcutaneous and omental adipose tissue in morbidly obese subjects. BMC Med Genomics. In press; 2010.

[8] Marrades, M.P.; González-Muniesa, P.; Martínez, J.A.; Moreno-Aliaga, M.J. A dysregulation in CES1, APOE and other lipid metabolism-related genes is associated to cardiovascular risk factors linked to obesity. Obes Facts. 3:312-318; 2010.

[9] Nagashima, S.; Yagyu, H.; Takahashi, N.; Kurashina, T.; Takahashi, M.; Tsuchita, T.; Tazoe, F.; Wang, X.L.; Bayasgalan, T.; Sato, N.; Okada, K.; Nagasaka, S.; Gotoh, T.; Kojima, M.; Hyodo, M.; Horie, H.; Hosoya, Y.; Okada, M.; Yasuda, Y.; Fujiwara, H.; Ohwada, M.; Iwamoto, S.; Suzuki, M.; Nagai, H.; Ishibashi, S. Depot-specific expression of lipolytic genes in human adipose tissues. J Atheroscler Thromb. 18:190-9; 2011.

[10] Roberts, D.W.; Aptula, A.O.; Patlewicz, G. Electrophilic chemistry related to skin sensitization. Reaction mechanistic applicability domain classification for a published data set of 106 chemicals tested in the mouse local lymph node assay. Chem Res Toxicol. 20:44-60; 2007.

[11] Python, F.; Goebel, C.; Aeby, P. Comparative DNA microarray analysis of human monocyte derived dendritic cells and MUTZ-3 cells exposed to the moderate skin sensitizer cinnamaldehyde.Toxicol Appl Pharmacol. 239:273-283; 2009.

[12] Kaspar, J.W.; Niture, S.K.; Jaiswal, A.K. Nrf2:INrf2 (Keap1) signaling in oxidative stress. 
Free Radic Biol Med. 47:1304-1309; 2009

[13] Natsch, A. The Nrf2-Keap1-ARE toxicity pathway as a cellular sensor for skin sensitizers-functional relevance and a hypothesis on innate reactions to skin sensitizers. Toxicol Sci. 113:284-292; 2010.

[14] Maruichi, T.; Fukami, T.; Nakajima, M.; Yokoi, T. Transcriptional regulation of human carboxylesterase $1 \mathrm{~A} 1$ by nuclear factor-erythroid 2 related factor 2 (Nrf2). Biochem Pharmacol. 79:288-295; 2010.

[15] Jung, K.A.; Kwak, M.K. The Nrf2 system as a potential target for the development of indirect antioxidants. Molecules. 15:7266-7291; 2010.

[16] Dinkova-Kostova, A.T.; Talalay, P. NAD(P)H:quinone acceptor oxidoreductase 1 (NQO1), a multifunctional antioxidant enzyme and exceptionally versatile cytoprotector. Arch Biochem Biophys. 501:116-123; 2010.

[17] Biswas, M.; Chan, J.Y. Role of Nrf1 in antioxidant response element-mediated gene expression and beyond. Toxicol Appl Pharmacol. 244:16-20; 2010.

[18] Malhotra, D.; Portales-Casamar, E.; Singh, A.; Srivastava, S.; Arenillas, D.; Happel, C.; Shyr, C.; Wakabayashi, N.; Kensler, T.W.; Wasserman, W.W.; Biswal, S. Global mapping of binding sites for Nrf2 identifies novel targets in cell survival response through ChIP-Seq profiling and network analysis. Nucl Acids Res. 38:5718-5734; 2010. 
[19] René, C.; Lopez, E.; Claustres, M.; Taulan, M.; Romey-Chatelain, M.C. NF-E2-related factor 2, a key inducer of antioxidant defenses, negatively regulates the CFTR transcription. Cell Mol Life Sci. 67:2297-309; 2010.

[20] Yamamoto, T.; Kyo, M.; Kamiya, T.; Tanaka, T.; Engel, J.D.; Motohashi, H.; Yamamoto, M. Predictive base substitution rules that determine the binding and transcriptional specificity of Maf recognition elements. Genes Cells. 11:575-291; 2006.

[21] Wasserman, W.W.; Fahl, W.E. Functional antioxidant responsive elements. Proc Natl Acad Sci U S A. 94:5361-5366; 1997.

[22] Maruta, S., Homma, K., Ohki, T. Conformational changes at the highly reactive cystein and lysine regions of skeletal muscle myosin induced by formation of transition state analogues. $J$ Biochem. 124:578-584; 1998.

[23] Mi L, Chung FL Binding to protein by isothiocyanates: a potential mechanism for apoptosis induction in human non small lung cancer cells. Nutr Cancer. 60 Suppl 1:12-20; 2008

[24] Shi, D.; Yang, J.; Yang, D.; LeCluyse, E.L.; Black, C.; You, L.; Akhlaghi, F.; Yan B. Antiinfluenza prodrug oseltamivir is activated by carboxylesterase HCE1 and the activation is inhibited by anti-platelet agent clopidogrel. J Pharmacol Exp Ther. 319:1477-1484; 2006.

[25] Xu, S.; Weerachayaphorn, J.; Cai, S.Y.; Soroka, C.J.; Boyer, J.L. Aryl hydrocarbon receptor and NF-E2-related factor 2 are key regulators of human MRP4 expression. Am J Physiol Gastrointest Liver Physiol. 299:G126-35; 2010. 
[26] Ose, A.; Ito, M.; Kusuhara, H.; Yamatsugu, K.; Kanai, M.; Shibasaki, M.; Hosokawa, M.; Schuetz, J.D.; Sugiyama, Y. Limited brain distribution of [3R,4R,5S]-4-acetamido-5-amino-3-(1ethylpropoxy)-1-cyclohexene-1-carboxylate phosphate (Ro 64-0802), a pharmacologically active form of oseltamivir, by active efflux across the blood-brain barrier mediated by organic anion transporter 3 (Oat3/SIc22a8) and multidrug resistance-associated protein 4 (Mrp4/Abcc4). Drug Metab Dispos. 37:315-321; 2009.

[27] Dawson, P.A.; Lan, T.; Rao, A. Bile acid transporters. J Lipid Res. 50:2340-2357; 2009.

[28] Wei, E.; Alam, M.; Sun, F.; Agellon, L.B.; Vance, D.E.; Lehner, R. Apolipoprotein B and triacylglycerol secretion in human triacylglycerol hydrolase transgenic mice. J Lipid Res. 48:2597-2606; 2007.

[29] Blais, D.R.; Lyn, R.K.; Joyce, M.A.; Rouleau, Y.; Steenbergen, R.; Barsby, N.; Zhu, L.F.; Pegoraro, A.F.; Stolow, A.; Tyrrell, D.L.; Pezacki, J.P. Activity-based protein profiling identifies a host enzyme, carboxylesterase 1 , which is differentially active during hepatitis $C$ virus replication. J Biol Chem. 285:25602-25612; 2010.

[30] Wang, H.; Wei, E.; Quiroga, A.D.; Sun, X.; Touret, N.; Lehner, R. (2010) Altered lipid droplet dynamics in hepatocytes lacking triacylglycerol hydrolase expression. Mol Biol Cell. 21:1991-2000; 2010.

[31] Siri-Tarino, P.W.; Sun, Q.; Hu, F.B.; Krauss, R.M. Saturated fat, carbohydrate, and cardiovascular disease. Am J Clin Nutr. 91:502-509; 2010. 
[32] Johnsen, O.; Murphy, P.; Prydz, H.; Kolsto, A.B. Interaction of the CNC-bZIP factor TCF11/LCR-F1/Nrf1 with MafG: binding-site selection and regulation of transcription. Nucleic Acids Res. 26:512-520; 1998.

[33] Jung, K.A., Kwak, M.K. The Nrf2 system as a potential target for the development of indirect antioxidants. Molecules. 15:7266-91; 2010.

[34] Keum, Y.S. Regulation of the Keap1/Nrf2 system by chemopreventive sulforaphane: implications of posttranslational modifications. Ann N Y Acad Sci. 1229:184-189; 2011.

[35] Li, Y,; Xie, M.; Song, X.; Gragen, S.; Sachdeva, K.; Wan, Y.; Yan, B. DEC1 negatively regulates the expression of DEC2 through binding to the E-box in the proximal promoter. $\mathrm{J}$ Biol Chem. 278:16899-16907; 2003.

[36] Liu, F.; Yang, D.; Song, X.; Deng, R.; Yan, B. The far and distal enhancers in the CYP3A4 gene coordinates the proximal promoter in responding to the pregnane $\mathrm{X}$ receptor similarly but differentially to hepatocyte nuclear factor-4 $\alpha$. Biochem J. 409:243-250; 2008.

[37] Li, Y.; Xie, M.; Yang, J.; Yang, D.; Deng, R.; Wan, Y.; Yan, B. The expression of antiapoptotic protein survivin is transcriptionally upregulated by DEC1 primarily through multiple Sp1 binding sites in the proximal promoter. Oncogene. 25:3296-3306; 2006.

[38] Zhu, W., Song, L., Zhang, H., Matoney, L., LeCluyse, E., Yan, B. Dexamethasone differentially regulates the expression of carboxylesterase genes in humans and rats. Drug Metab Dispos. 28:186-191; 2000. 
[39] Yang, J.; Shi, D.; Yang, D.; Song, X.; Yan, B. Interleukin-6 suppresses the expression of carboxylesterases HCE1 and HCE2 through transcriptional repression. Mol Pharmacol. 72:686$694 ; 2007$.

[40] Yang, D.; Shi, D.; Yang, J.; Deng, R.; Yan, B. Scoparone potentially transactivates the bile salt export pump gene and the potentiation is enhanced by cytochrome P450 1A2 but inhibited by protein kinase C inhibitor. Brit J Pharmacol. 164:1547-1557; 2011. 
Table I Sequences of Oligonucleotides

\begin{tabular}{ll}
\hline Oligonucleotide & \multicolumn{1}{c}{ Sequence } \\
\hline Native promoter reporters & \\
CES1A1-6560-Mlul & 5'-CTGCAACCTTCCCATCTCAGCTGTGACCCA-3' \\
CES1A1-6448-Mlul & 5'-AGCTAATGAATAGGATCTGGGTTATAATC-3' \\
CES1A1-5017-Mlul & 5'-CAATACCCTAATTTCGATCTCTGAATGACC-3' \\
CES1A1-3582-Mlul & 5'-TATTGCTTACAGCTGAAGTG-3' \\
CES1A1-3432-Mlul & 5'-CAGGCAAAACCTAGGAGTGG-3' \\
CES1A1-2293-Mlul & 5'-TGATTAGAATATCTTCCTGATGTATAAAAG-3' \\
CES1A1-1426-Mlul & 5'-GATGTTTCCAGCTTCATCCACGTTGTAGC-3' \\
CES1A1-3552-Mlul & 5'-GTTATATGTATTAAGCAAAA-3' \\
CES1A1-3532-Mlul & 5'-TTAGATCTATTGTAAGGCT-3' \\
CES1A1-3512-Mlul & 5'-TGGTAGGCTCCAGCCTCACC-3' \\
CES1A1-3492-Mlul & 5'-CATCACAATCTGCAGAGTCA-3' \\
CES1A1-3482-Mlul & 5'-TGCAGAGTCATCATGAAGCA-3' \\
CES1A1-10484Xhol & 5'-ATACACTCGAGTCGGGGCCTGCGAGGTCTCTGTGCA- \\
& GTTCA-3' \\
Element reporters & 5'-CACAATCTGCAGAGTCATCATGAAG-3' \\
CES1A1-S/ARE & 5'-TTAAGATCGTGAGACAGCATTAATC-3' \\
CES1A1-ARE4 & 5'-CACAATCTGCAGAATCATCATGAAC-3' \\
CES1A2-S/ARE & 5'-TTGATGCAGTCAGGGTGACTCAGCAGCT-3 \\
AKR1C2-ARE & 5'-GAAGACAATGACTAAGCAGAAATC-3' \\
GCLM-ARE & 5'-CCTCCCCGTGACTCAGCGCTTTGT-3' \\
GCLC-ARE & 5'-AGTCACAGTGACTCAGCAGAATCT-3' \\
NQO1-ARE & 5'- TATTGCTAGCCTGAAGTGTTGCAGGGGAGTT-3' \\
EMSA & 5'-ATAAGCTAGCTGAGTTGAGCCTATGTATTAG-3' \\
CES1A1-S/ARE & 5'-CACAATCTGCAGAGTCATCATGAAG-3' \\
CES1A1-S/ARE(mutant) & 5'-CACAATGTACTGAGGAATCATGAAG-3' \\
CES1A1-ARE4 & 5'-TTAAGATCGTGAGACAGCATTAATC-3' \\
ChIP & \\
P1 & \\
P3 &
\end{tabular}




\section{LEGENDS FOR FIGURES}

Fig. 1. Induction of CES1 by SFN and TNBS in human dermal fibroblast, human primary hepatocyte, and skin sarcoma line HT1080 and hepatoma line Huh7 Cells were cultured in 12-well plates and were treated with SFN $(10 \mu \mathrm{M})$, TNBS $(10 \mu \mathrm{g} / \mathrm{ml})$ or DMSO for $24 \mathrm{~h}$. Total RNA was isolated and subjected to qRT-PCR analysis for the level of CES1 mRNA (A-D) by Taqman probes as described in the section of Materials and Methods. The signals from each target were normalized based on the signal from GAPDH and polymerase II and expressed as mean \pm SD. Four individual donors were tested on human dermal fibroblasts, five on human hepatocytes and three separate experiments were performed on cell lines. The asterisk signs indicate statistical significance $(P<0.05)$ from DMSO-treated cells. To determine the corresponding induction at the protein level, lysates $(20 \mu \mathrm{g})$ from control and treated Huh7 cells were subjected to SDS-PAGE and transferred electrophoretically to Trans-Blot nitrocellulose membranes. The immunoblots were blocked in 5\% non-fat dry milk, incubated with the antibody against CES1 or GAPDH. The blots were detected with chemiluminescent substrate (E).

Fig. 2. Identification of sensitizing/antioxidant response element $\underline{(A) \text { Activation of CES1A1 }}$ reporters by SFN, TNBS or Nrf2 Huh7 cells in 48 well-plates were transiently transfected by GenJet version II. For the SFN and TNBS treatment experiment, the transfection mixture contained $50 \mathrm{ng}$ of a reporter and $0.2 \mathrm{ng}$ of the CMV-Renilla luciferase plasmid. After incubation at $37^{\circ} \mathrm{C}$ for $12 \mathrm{~h}$, the transfected cells were treated with SFN $(10 \mu \mathrm{M})$, TNBS $(10$ $\mu \mathrm{g} / \mathrm{ml}$ ) or the same volume of DMSO for $24 \mathrm{~h}$. Luciferase activities were determined with a Dual-Luciferase Reporter Assay System and the reporter activity was expressed as fold of activation. For the Nrf2 experiment, the transfection mixture contained $50 \mathrm{ng}$ of a reporter and $0.2 \mathrm{ng}$ of the CMV-Renilla luciferase plasmid, along with $10 \mathrm{ng}$ Nrf2 expression construct or the corresponding vector. $(B)$ Identification of CES1A1 Nrf2 response element To further narrow 
down the sequence that supports the responsiveness to Nrf2, the CES1A1-3582-Luc was further shortened from the 5 ' end by 20 or 10 bases, and cotransfection was then performed as described above. Data were collected from three independent experiments.

Fig. 3. Analyses of the SIARE element by EMSA and ChIP (A) EMSA analysis Nuclear extracts $(5 \mu \mathrm{g})$ from Huh7 cells treated with SFN $(10 \mu \mathrm{M})$ were incubated with a biotinylated probe containing the S/ARE element $(0.1 \mathrm{pmol})$ for $20 \mathrm{~min}$. In the competition assay, nuclear extracts were pre-incubated with the unlabeled S/ARE element, S/ARE mutant or ARE4 at 25x or $100 x$ excess for $5 \mathrm{~min}$, and then incubated with the biotinylated probe. In disruption assay, nuclear extracts were incubated first with an antibody against Nrf2 on ice for 20 min and then with the biotinylated probe. The protein-DNA complexes were electrophoretically resolved and transferred to a Biodyne $\AA$ nylon membrane. The biotinylated probe was located with streptavidin-conjugated horseradish peroxidase and chemiluminescent substrate. (B) ChIP analysis Huh7 Cells were treated with SFN $(10 \mu \mathrm{M})$ for $24 \mathrm{~h}$, washed and underwent crosslinking for $15 \mathrm{~min}$ by $1 \%$ formaldehyde, and the cross-linking was terminated with $125 \mathrm{mM}$ glycine. The soluble chromatins were prepared, pre-cleared with protein $G$ beads and incubated with anti-Nrf2 antibody or pre-immune lgG. The antibody-bound chromatins and DNA input (1/20 of the antibody-bound chromatins) were analyzed by PCR for the presence of the genomic fragments containing the Nrf2-bound element with the primers indicated in the diagram. The primer sequences are shown in Table I.

Fig. 4. Functional characterization of the SIARE element (A) Activation of S/ARE containing or disrupting reporter by SFN Huh7 cells were transiently transfected by a reporter (50 ng) of the S/ARE-Luc, CEA1A1-3582-Luc or its mutant CES1A1-3582m-Luc along with $0.2 \mathrm{ng}$ of the CMV-Renilla luciferase plasmid. After incubation at $37^{\circ} \mathrm{C}$ for $12 \mathrm{~h}$, the transfected cells were treated with SFN $(0-10 \mu \mathrm{M})$ or the same volume of DMSO for $24 \mathrm{~h}$. Luciferase activities were 
determined and the reporter activity was expressed as fold of activation. (B) Activation of S/ARE containing or disrupting reporter by TNBS Huh7 cells were transiently transfected as described above but treated with TNBS $(0-10 \mu \mathrm{g} / \mathrm{ml})$. Likewise, the reporter activities were determined. (B) Activation of S/ARE containing or disrupting reporter by Nrf2 Huh7 cells were transiently transfected with $50 \mathrm{ng}$ reporter and $0.2 \mathrm{ng}$ of the CMV-Renilla luciferase plasmid along with 0-20 ng Nrf2 expression construct. The corresponding vector was used to equalize the amount of total plasmid. The luciferase activities were determined 24 after the transfection. *Statistically significant from the controls.

Fig. 5. Differential activation of various ARE reporters by Nrf1 and Nrf2 Huh7 cells were transiently transfected by a reporter $(50 \mathrm{ng})$ and the CMV-Renilla luciferase plasmid $(0.2 \mathrm{ng})$ along with $10 \mathrm{ng} \mathrm{Nrf1,} \mathrm{Nrf2}$ or the vector. The luciferase activities were determined $24 \mathrm{~h}$ after the transfection. The core-Nrf2 sequence from known Nrf2 target genes is shown in $\mathrm{H}$.

Fig. 6. Diagrammatical presentation of regulated transcription of the CES1A1 through the SIARE and ARE4 elements The relative width of the arrows between Nrf2 to small Maf and Nrf2 to YY1 suggests the dominance of the formation of Nrf2-Maf dimmers over that of Nrf2YY1 dimers. The double ended arrow between the Nrf2-YY1 dimers and the YY1-Nrf2 composite element suggests weak interaction. The dotted lines indicate possible direct interactions. 
A

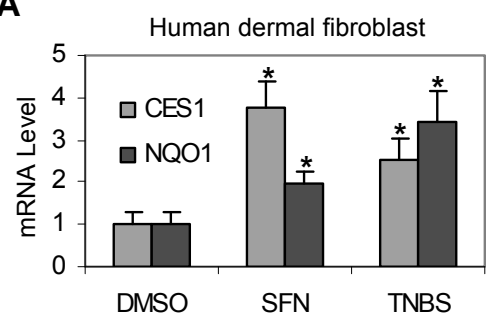

C

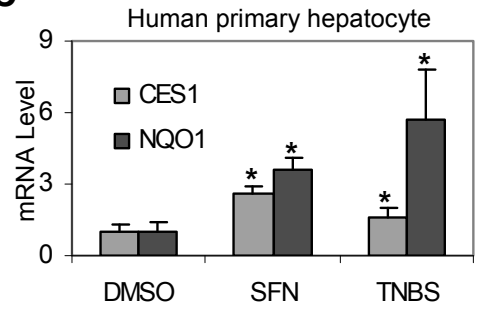

B

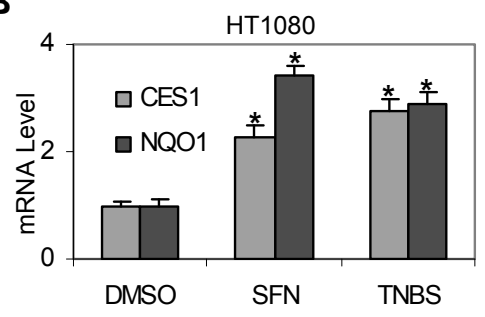

D

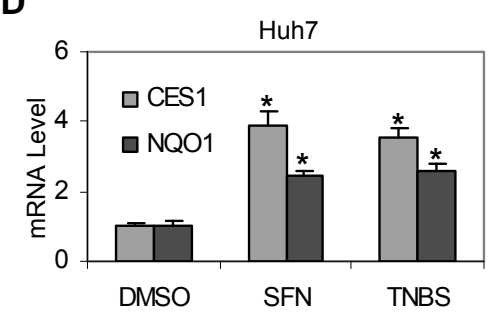

E

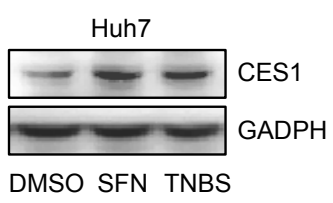

Fig. 1. Yan (2011) 
A

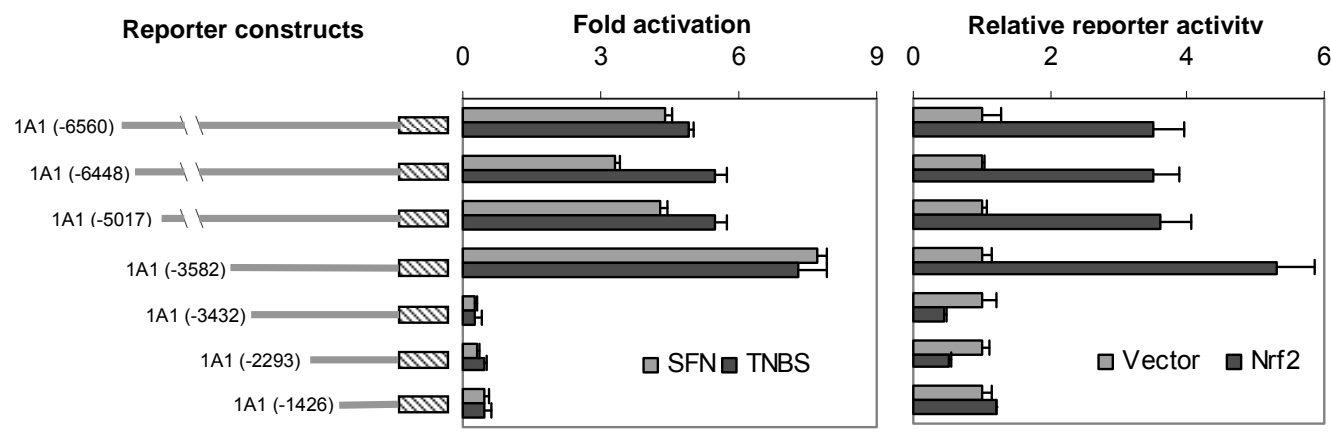

B

Reporter constructs

Fig. 2. Yan (2011) 
A

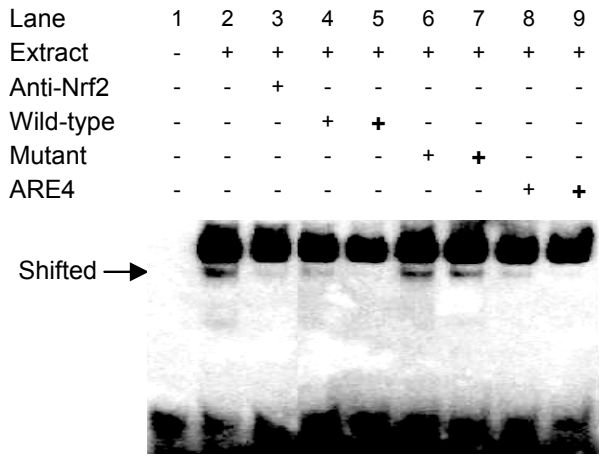

B

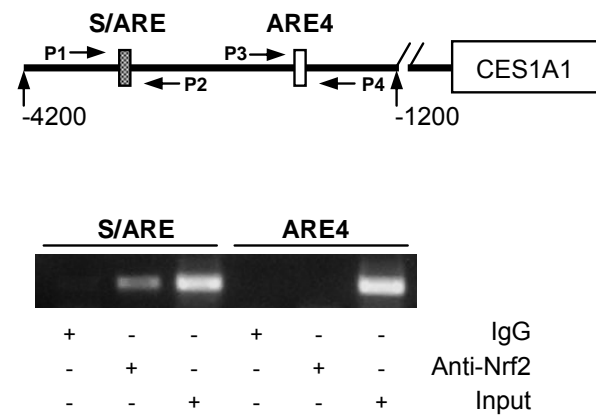

Fig. 3, Yan (2011) 
A

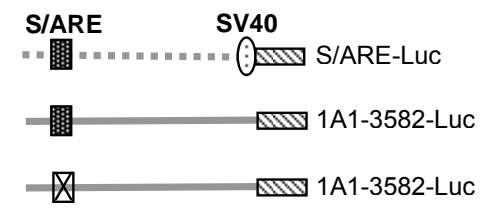

B

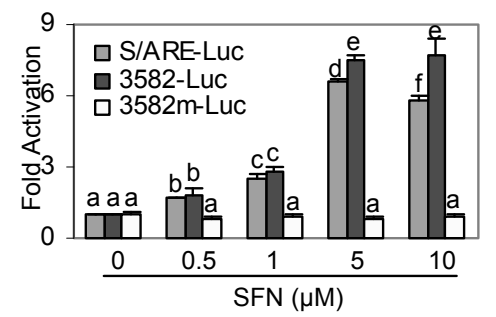

C

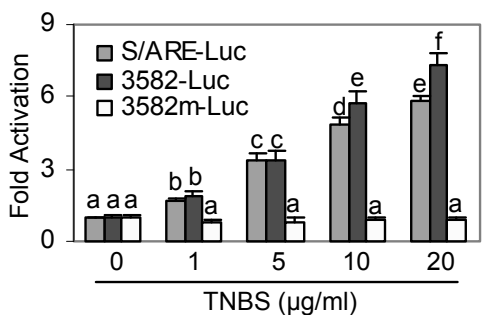

D

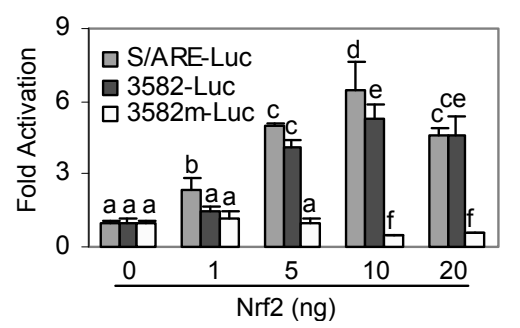

Fig. 4, Yan (2011) 
A

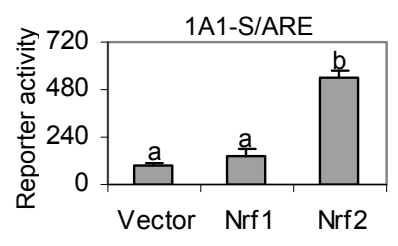

C

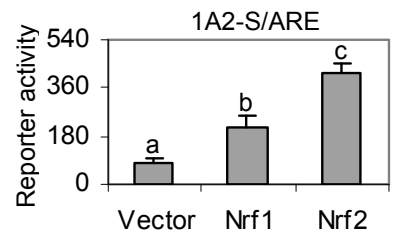

E

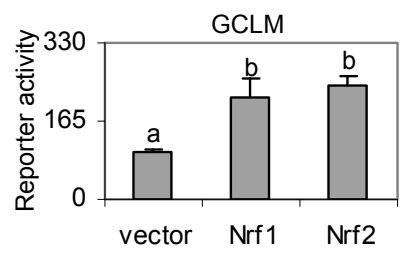

G

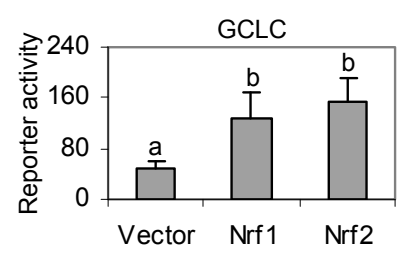

B

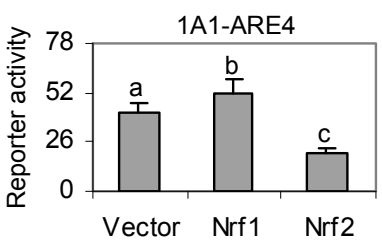

D

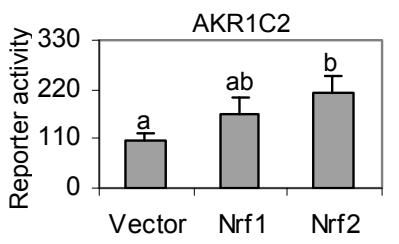

F

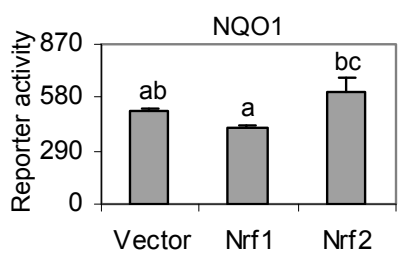

$\mathrm{H}$

\begin{tabular}{ll}
\hline Nucleotide & 1234567890 \\
1A1-S/ARE : & TGCAGAGTCA \\
1A1-S/ARE-R: & TGACTCTGCA \\
1A1-ARE4: & TGAGACAGCA \\
1A2-S/ARE : & TGCAGAATCA \\
1A2-S/ARE-R: & TGATTCTGCA \\
AKR1C2-ARE: & TGACTCAGCA \\
GCLM-ARE: & TGACTAAGCA \\
GCLC-ARE: & TGACTCAGCG \\
NQ01-ARE: & TGACTCAGCA \\
Consensus: & TGACTCAGCA
\end{tabular}

Fig. 5, Yan (2011) 

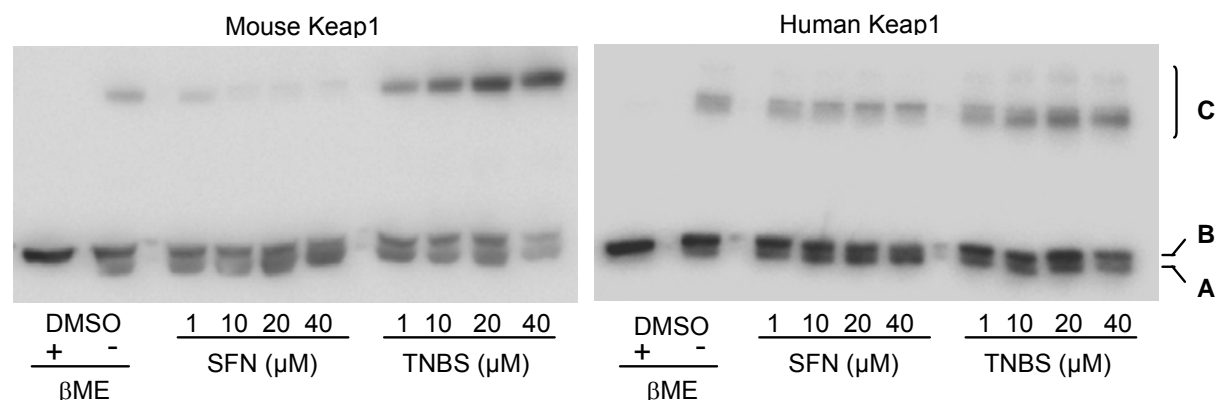

A: Oxidized intramolecular keap1; B: Reduced keap1; C: Oxidized intermolecular keap1; DMSO: Dimethyl sulfoxide; $\beta$ ME: 2-mercaptoethanol; SFN: sulforaphane; TNBS: trinitrobenzene sulfonate

Fig. 1. Reactivity of mouse and human Keap1 toward sulforaphane and trinitrobenzene sulfonate 
Chen et al. (2012)

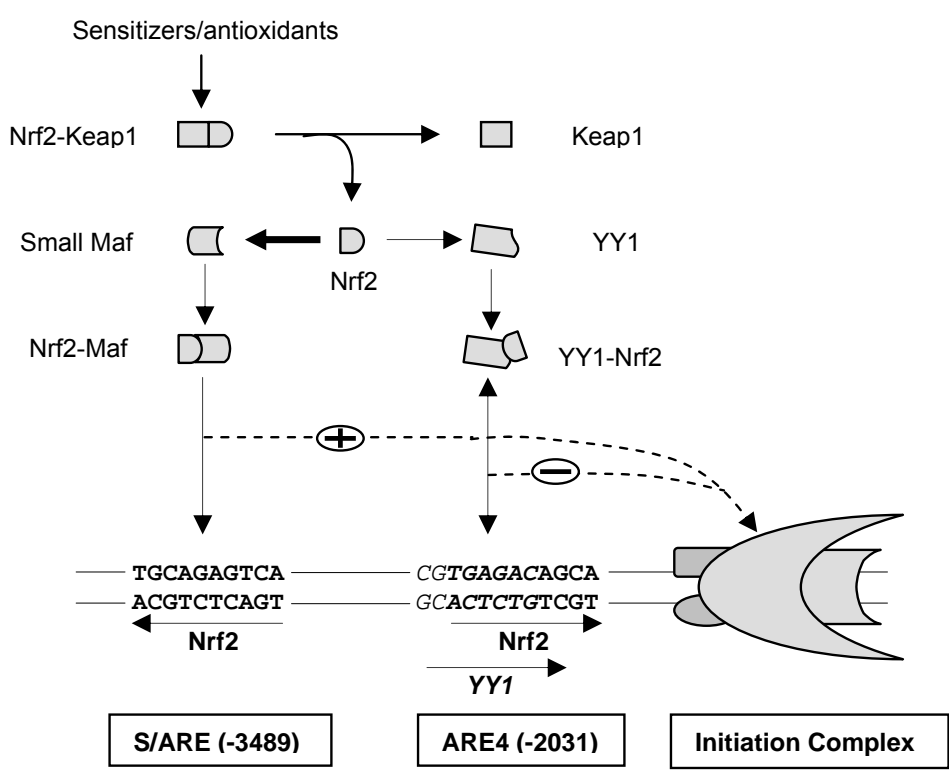

Fig. 6, Yan (2011) 